Dialectologia. Special issue, IX (2021), 253-284.

ISSN: 2013-2247

Received 19 January 2021.

Accepted 30 January 2021.

\title{
LOS SUFIJOS EN LOS GENTILICIOS CATALANES. UNA APROXIMACIÓN CONTRASTIVA ${ }^{1}$
}

\author{
Maria-Pilar PEREA \\ Universitat de Barcelona * \\ mpilar.perea@ub.edu
}

Resumen

La cartografía automática de los cuadernos de campo de Antoni M. Alcover <alcover.iec.cat>, facilita el acceso a numerosos materiales dialectales que fueron recopilados durante el primer tercio del siglo XX. Estos aportan un conocimiento indispensable para la historia de la lengua catalana en sus diversas vertientes.

En el ámbito del léxico, los datos muestran el vocabulario específico de diversos campos semánticos, así como informaciones relacionadas con la antroponimia y la toponimia. Partiendo de este último campo de investigación, los cuadernos incluyen un número considerable de gentilicios, que a menudo presentan variantes gráficas.

El objetivo de este trabajo es estudiar la estructura de los sufijos que forman los gentilicios a partir de los datos aportados por los citados materiales. Estos se completarán con los que aparecen en proyectos llevados a cabo en esa misma época: el Diccionari català-valencià-balear (DCVB) y el Atlas Lingüístico de la Península Ibérica $(A L P I)$. Se pretende también ofrecer una muestra de la distribución y el uso de los gentilicios a principios del siglo XX, que permitirá en el futuro la ejecución de trabajos más completos de tipo comparativo.

\footnotetext{
${ }^{1}$ Este trabajo se adscribe al proyecto PGC2018-095077-B-C43, financiado por el Ministerio de Ciencia, Innovación y Universidades.

* Departament de Filologia Catalana i Lingüística General, Facultat de Filologia i Comunicació. Gran Via de les Corts Catalanes 585, 08007 Barcelona.
} 


\section{Palabras clave}

gentilicios, sufijos, geolingüística, Diccionari català-valencià-balear, Atlas Lingüístico de la Península Ibérica

\section{SUFFIXES IN THE CATALAN DEMONYMS. A CONTRASTIVE APPROACH}

Abstract

The automated mapping of the Antoni M. Alcover's notebooks <alcover.iec.cat>, allows to access to numerous dialect materials collected during the first third of the 20th century. These provide essential knowledge for the history of the Catalan language.

Concerning lexicon, the data show the specific vocabulary of various semantic fields, as well as general information related to anthroponymy and toponymy. Starting from this last field of research, the notebooks include a considerable number of placenames, which often present graphic variants.

The main aim of this work is to study the structure of the suffixes that form the demonyms from the data provided by the aforementioned materials. These will be completed with those appearing in other contemporary projects: the Diccionari català-valencià-balear (DCVB) and the Atlas Lingüístico de la Península Ibérica $(A L P I)$. It is also intended to offer a sample of the distribution and use of the placenames at the beginning of the 20th century, which will allow the execution of more complete comparative studies in the future.

\section{Keywords}

demonyms, suffixes, geolingüistics, Diccionari català-valencià-balear, Atlas Lingüístico de la Península Ibérica

\section{Introducción}

La cartografía automática de los cuadernos de campo de Antoni M. Alcover (1862-1932), que puede consultarse en el Portal dedicado al citado dialectólogo, con sede en el Institut d'Estudis Catalans (<http://alcover.iec.cat/>), facilita el acceso a numerosos materiales dialectales que fueron recopilados durante el primer tercio del siglo XX. Estos aportan un conocimiento indispensable para la historia de la lengua catalana en sus diversas vertientes.

Desde el ámbito del léxico, los datos dialectales muestran el vocabulario específico de diversos campos semánticos, así como informaciones relacionadas con la antroponimia y la toponimia. Partiendo de este último campo de investigación, los 
cuadernos incluyen un número considerable de gentilicios, que a menudo presentan variantes gráficas. Cabe destacar que Alcover, en sus viajes filológicos, visitó más de mil localidades.

El objetivo de este trabajo es estudiar la estructura de los sufijos que forman los gentilicios, basándose, inicialmente, en los datos aportados por los citados cuadernos. Estos incluyen unas doscientas designaciones de los habitantes de lugares, y a partir de su agrupación y estudio podrá trazarse una panorámica del uso de los sufijos, la cual se completará con los gentilicios que aparecen en proyectos llevados a cabo en esa misma época: el Diccionari català-valencià-balear y los cuadernos que conforman el Atlas Lingüístico de la Península Ibérica (ALPI), cuya informatización completa se está desarrollando actualmente. Se pretende también ofrecer una muestra de la distribución y el uso de los gentilicios a principios del siglo XX, lo cual permite el desarrollo de trabajos más completos de tipo comparativo.

\section{Los gentilicios en los cuadernos de campo}

Al consultar los gentilicios que aparecen cuando se efectúa la cartografía de los datos de los cuadernos de campo (CC) se muestra un mapa (Mapa 1) que incluye 155 denominaciones correspondientes a los habitantes de diferentes localidades del dominio lingüístico catalán, las cuales incorporan los sufijos más habituales (Véase el Anexo 1): -à (Almatret, almatretà), -er (Benidorm, benidormer), -enc (Vila, vilenc), -ès (Maó, maonès), -í (Pego, pegotí), -ol (Figuera, figuerol), etc.; y otros minoritarios: -ut (Biar, biarut), -ó (Búger, bujarró); así como localidades que no tienen gentilicio (Agullana, els d'Agullana).

Se observan también algunos paragentilicios (Sant Ferran de Formentera: "Hi ha els estanys (es pudent $\mathrm{i}$ es des peix, que pertanyen a Sant Ferran de Formentera): estanyers") y ocasionalmente alternancia de gentilicios (Sant Agustí: agustiner o agustinenc; Elx: "elxeros. Els d'Elx los diuen «elxeros», ${ }^{2}$ pero ells no s'hi diuen, se diuen

\footnotetext{
${ }^{2}$ Elxero también está documentado en Giner, apud Casanova (2001: 39).
} 
«ilicitans»; però això es un mot erudit"). ${ }^{3}$ En algunos casos la denominación proviene de la situación geográfica de la localidad (en Ibiza, es d'aqueixus amuns (amunt = arriba, refiriéndose a áreas elevadas)).

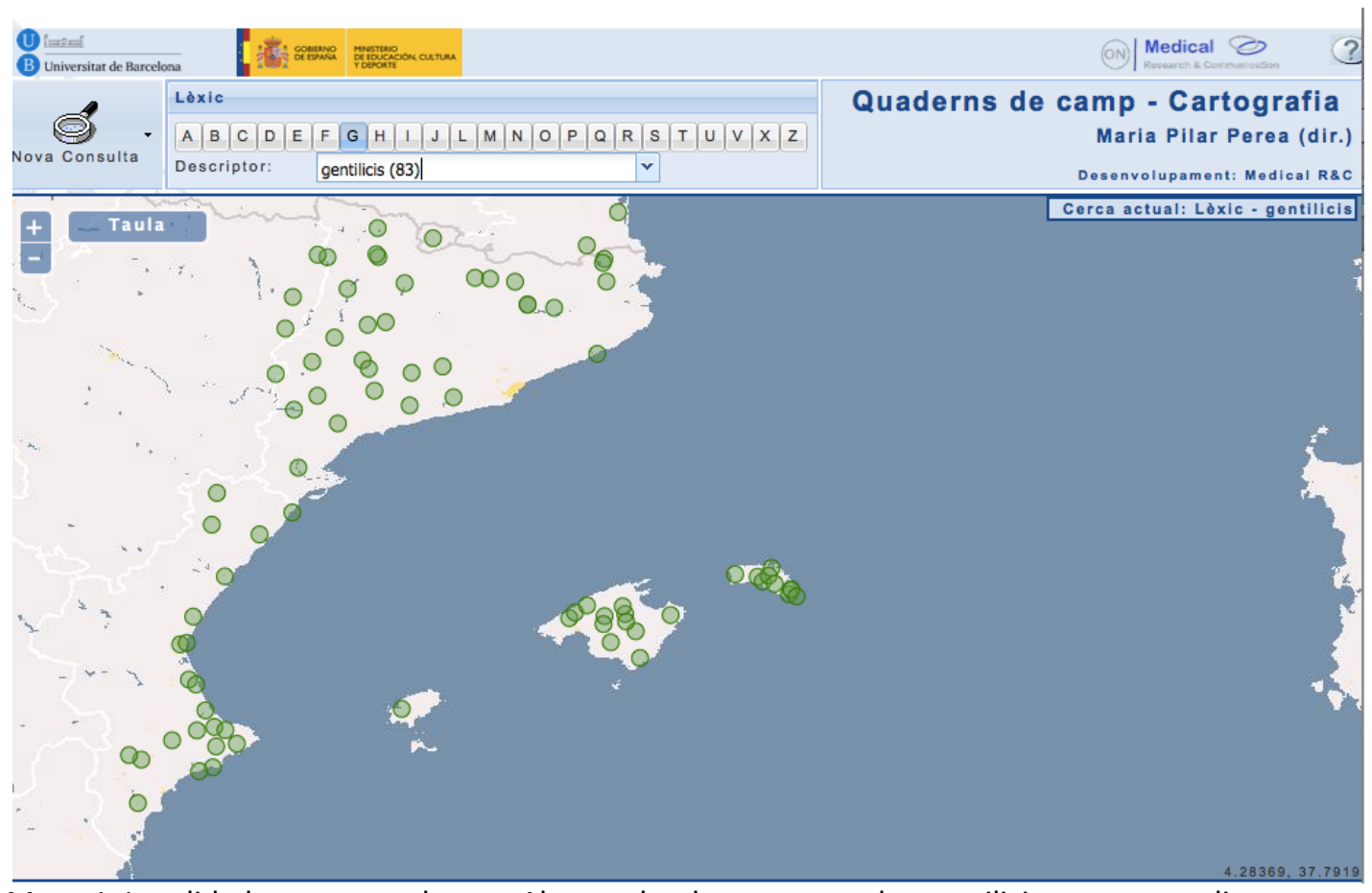

Mapa 1. Localidades encuestadas por Alcover donde se recogen los gentilicios correspondientes.

Las formas alternativas pueden ser un gentilicio y un apodo formado por la alteración del primero. Es el caso de la localidad de Santa Eugènia de Mallorca, donde convivían los gentilicios Sant-Euginians y taujans, el último de los cuales, ahora vigente, puede explicarse como una deformación del primero, como indica el DCVB (s.v. taujà): "Nadiu de la vila de Santa Eugènia (Mall.), segons denominació que els donen en els pobles circumdants. Sembla derivat humorístic de (san) taeugè(nia), format per analogia de taujà art. 1" (Mancat de agudesa mental i de malícia; curt d'enteniment i d'acció). ${ }^{4}$

En algunos casos, tanto en singular como en plural, aparecen dos formas alternativas: patroner / patronero (Patró) o calers / caleros (Sa Cala, Eivissa). Por otro lado, un mismo topónimo puede generar, en áreas distintas, gentilicios con diferentes sufijos; así, los habitantes de Vilafranca de Bonany son vilafranquers mientras que los

\footnotetext{
${ }^{3}$ Véase Biosca (2010) para el estudio de los gentilicios de Elche, elxà i il/licità.

${ }^{4}$ Gabriel Bibiloni (<http://bibiloni.cat/blog/?p=922>) polemiza en su bloc sobre el estatus o no de gentilicio de la palabra 'taujà'.
} 
de Vilafranca del Penedès son vilafranquins, hecho que demuestra la arbitrariedad la adición de los sufijos a sus bases.

Algunas de las formas registradas por Alcover tienen especial interés porque recogen gentilicios de localidades pequeñas o de áreas muy reducidas (especialmente de las Baleares), que no suelen aparecer en los repertorios ni en los diccionarios de gentilicios convencionales (muleros / mulers (de la Mola, Formentera)). Ocasionalmente, también hay información sobre su uso o vigencia. Así a es Migjorn Gran: migjornenc (antic) / migjorner, ra o a Mahón: maonenc (antic) / maonès, que podrían indicar que las formas en -enc ${ }^{5}$ fueron las primeras y han sido substituidas por otros sufijos.

La observación de estos datos suscita, en principio, dos preguntas: a) si se mantienen actualmente en todos los casos estas denominaciones (puesto que fueron recogidas a principios del siglo $X X), y, b)$ si, en el uso de un gentilicio, existe una relación entre área geográfica y frecuencia de aparición de un determinado sufijo.

Otro aspecto destacable está relacionado con algunos comentarios que acompañan la denominación de los gentilicios, en los cuales Alcover distingue, como lo harán también el $A L P I$ y el $D C V B$, entre la manera como se denominan los habitantes de una población a sí mismos y como son estos denominados. Un ejemplo lo tenemos en la forma "elxero", que reciben los habitantes de Elche. Parece que los gentilicios, y más si se trata de apodos y términos despectivos, surgieron a partir del modo en que los habitantes de pueblos cercanos llamaban a los habitantes de una determinada localidad.

\section{Un nuevo elenco de gentilicios de la primera mitad del siglo XX: el ALPI y el DCVB}

Actualmente, hay numerosos repertorios (véase § 4) que recopilan los gentilicios correspondientes a todas las localidades del dominio catalán con la finalidad de ofrecer una información adecuada para estudiantes o para personas interesadas que

\footnotetext{
${ }^{5}$ También la Guia de gentilicis del Parlament de Catalunya indica que a Brunyola (Cat), el sufijo -enc es antiguo y da la forma de genitivo como solución alternativa.
} 
quieran consultarlos. Su conjunto recibe en este trabajo la abreviatura "ON". Sin embargo, no es frecuente que aparezca información sobre el proceso de recogida de datos: si los gentilicios se extrajeron de publicaciones ya existentes (como parece sugerir, en algunos casos, la bibliografía que consta al final de la publicación) o si fueron el resultado de encuestas. Puesto que nos interesaba esta última metodología, hemos recurrido a dos nuevas fuentes de información para complementar los gentilicios citados en el apartado anterior: el Atlas Lingüístico de la Península Ibérica $(A L P I)$ y el Diccionari català-valencià-balear $(D C V B)$. En este último caso, sólo se han consultado los que corresponden a las localidades que fueron visitadas por Alcover, para tener la certeza que fueron obtenidas presumiblemente de primera mano.

El ALPI aporta 103 gentilicios (Véase el Anexo 2), ${ }^{6}$ recogidos en su forma plural, solución usada con más frecuencia y que permite hacer posteriores consideraciones de tipo fonético y morfológico. Se aprecia igualmente la presencia de los sufijos habituales: -enc (Agullana, gullanencs), -er (Felanitx, felanitxers), -à (Falset, falsetans), ès (Clariana, clarianès), -í (Alcora, alcorí), -ol (Figuera, figuerol), y también de otros de carácter minoritario: -ot (Salses, salsirot, así como localidades que no tienen gentilicio (Alàs, No hay nombre ni para el pueblo ni para la comarca). También aparecen apodos (Viladecavalls: trumbaire) ${ }^{7}$ o formas despectivas (Vilar de Canes: Ilangostes). No se registran, sin embargo, soluciones alternativas de gentilicios. Ocasionalmente se indican las formas poco usadas: Massalavés: massalavesseros poco usado.

Aunque existen, mayoritariamente, coincidencias en las localidades que fueron encuestadas en los dos proyectos citados, en algunos casos, se observan discrepancias respecto a los gentilicios registrados por Alcover. Así, en Agullana, mientras los CC recogen la forma de genitivo como gentilicio, el ALPI registra gullenc. Tampoco hay coincidencias en Campdevànol (CC: campdevanoler; ALPI: campdevanolenc). En

\footnotetext{
${ }^{6}$ Se incluyen, en el área valenciana, las localidades de habla castellana (Ademuz, Azuébar, etc.), cuyos gentilicios contienen el sufijo -ero, también presente en localidades del País Valenciano y del sur de Cataluña.

${ }^{7}$ Como hipótesis, el apodo trumbaire procedería de la deformación de un nombre local que habría tenido la población, La Tarumba. Según Salvador Cardús, La Tarumba proviene de los que fueron a vivir a la población, que pertenecían a una casa que todavía hoy se llama Cal Tarumbot. (cf. <http://www.geocities.ws/toponimia_valles/pobles/viladecavalls/html/origen.html>).
} 
Mahón, el $A L P I$ incluye una forma metatizada: manuès, ${ }^{8} \mathrm{y}$ el sufijo coincide con la forma considerada no antigua que recogió Alcover: maonès.

La discordancia en Organyà (CC: organyanès; ALPI: ganxos ${ }^{9}$ (nombre jocoso que les dan los de los pueblos vecinos)) refrenda que la motivación de los gentilicios viene dada por los habitantes de los pueblos vecinos más que por la propia denominación de los locales.

Del $D C V B$, se han consultado 852 gentilicios, que corresponden a algunas de las localidades que Alcover visitó. En ciertos casos en el Diccionari se indica la fuente de donde se obtiene el gentilicio. Se observan escasas discrepancias, en los pocos enclaves coincidentes, entre las formas del $A L P I$ y del DCVB: p. e., Senterada ( $A L P I$ : muntanyesos de Senterada; DCVB: senteradí) o Sineu (ALPI: sinevès; DCVB: sineuer).

\section{Otros repertorios de gentilicios catalanes}

A continuación se comparan los datos descritos hasta ahora con los que aparecen en repertorios relativamente recientes (en particular, se ha consultado el Diccionari dels gentilicis catalans, de August Bover, las listas de gentilicios publicadas por la Societat d'Onomàstica <https://www.onomastica.cat/> (SO), que incluyen los de los municipios catalanes, de los valencianos, de las Islas Baleares, de la Cataluña del Norte y de Aragón, y la Guia de topònims i gentilicis, publicación actualizada en 2018 del Parlament de Catalunya < https://www.parlament.cat/document/intrade/6281>, cuyos resultados no siempre coinciden). El conjunto de estas publicaciones recibe en este trabajo la abreviatura "ON". En total, se han registrado 1.841 gentilicios correspondientes a todo el dominio de habla catalana, que presentan la siguiente distribución: 924 pertenecen a Cataluña, 71 a las Baleares, 202 a la Cataluña del Norte, 547 a Valencia, 7 a Andorra y 63 a Aragón. La comparación entre los datos de las

\footnotetext{
${ }^{8}$ No se consideran en este trabajo aspectos fonéticos que puedan afectar la base del gentilicio mientras se aplique el mismo sufijo; por ejemplo, en Alaior: CC: alaurenc; ON: alaiorenc, - $a$ o en Benidoleig: DCVB: beniloditjà; ON: benidolejà, -ana, que, en los trabajos de Alcover, pretenden mostrar la pronunciación real.

${ }^{9}$ Véase en <http://enricxicoy.blogspot.com.es/2007/05/organy-els-ganxons.html>, los orígenes de la leyenda que originó que los habitantes de Organyà recibiesen el sobrenombre de ganxos.
} 
distintas fuentes permite constatar ciertas diferencias que pueden sistematizarse del modo siguiente:

a) las soluciones que ofrecen los CC de Alcover discrepan por diversos motivos de los gentilicios indicados por otros repertorios (Tabla 1):

\begin{tabular}{|c|c|c|c|c|}
\hline Localidad & $\mathrm{CC}$ & $A L P I$ & $D C V B$ & ON \\
\hline Agullana (Cat) & $\begin{array}{l}\text { els d'Agullana, els de } \\
\text { Darnius (els de Darnius, els } \\
\text { de Figueres }\end{array}$ & gullenc & & agullanenc, - $a$ \\
\hline $\begin{array}{l}\text { Anna (la Canal de } \\
\text { Navarrés) (Val) }\end{array}$ & anneros & & & anner, - $a$ \\
\hline Biar (Val) & biarut & biaruts & & $\begin{array}{l}\text { biarenc, }-a \\
\text { biarut, -uda }\end{array}$ \\
\hline Campdevànol (Cat) & campdevanoler & campdevanolencs & & $\begin{array}{l}\text { campdevanolenc, } \\
-a\end{array}$ \\
\hline Elx (Val) & $\begin{array}{l}\text { elxeros. Els d'Elx los duen } \\
\text { "elxeros", pero ells no s'hi } \\
\text { diuen, se diuen "ilicitans»; } \\
\text { però això es un mot erudit. }\end{array}$ & & & $\begin{array}{l}\text { il.licità, -ana / } \\
\text { elxà, -ana }\end{array}$ \\
\hline Esporles (Bal) & vilero / esporlerí & & & esporlerí, -ina \\
\hline Figuera, la (Cat) & figuerol & & figuerenc & figuerenc, $-a$ \\
\hline Formentera (Bal) & $\begin{array}{l}\text { formenterencs } \\
\text { formenterer / formenters }\end{array}$ & & & formenterer, - $a$ \\
\hline $\begin{array}{l}\text { Migjorn Gran, es } \\
\text { (Bal) }\end{array}$ & migjornenc (antic) & & & migjorner, $-a$ \\
\hline $\begin{array}{l}\text { Santa Eulària des } \\
\text { Riu (Bal) }\end{array}$ & santaeulariencs & & $\begin{array}{l}\text { santaeula- } \\
\text { rienc, } \\
\text { santaeula- } \\
\text { rier }\end{array}$ & $\begin{array}{l}\text { eularienc, } \quad-a ; \\
\text { santeularier, }-a\end{array}$ \\
\hline Solsona (Cat) & solsoninsos & & $\begin{array}{l}\text { solsonès, } \\
\text { solsoni, } \\
\text { solsonenc }\end{array}$ & $\begin{array}{l}\text { solsonenc, } \\
\text { solsoní, -ina }\end{array}$ \\
\hline
\end{tabular}

Tabla 1. Discrepancias en la denominación de los habitantes de una localidad en cuatro corpus de datos.

Alcover incluye cuatro gentilicios cuya forma masculina acaba en -o: anneros, elxeros, vilero y solsoninsos, que no aparecen en las formas de ON. En algunos casos, los repertorios ofrecen formas de gentilicio alternativas, sin indicar si el uso de una o de otra es paralelo o depende de cuestiones relacionadas con la antigüedad, etc. Llama la atención que Alcover incorpore soluciones como figuerol o formenter. 
Dialectologia. Special issue, IX (2021), 253-284.

ISSN: 2013-2247

b) Los gentilicios del ALPI discrepan de las otras soluciones (Tabla 2):

\begin{tabular}{|c|c|c|c|c|}
\hline Localidad & $\mathrm{CC}$ & $A L P I$ & $D C V B$ & ON \\
\hline Ademús (Val) & & ademuceros & & ademusser, $-a$ \\
\hline Alberic (Val) & & alberiqueny & & $\begin{array}{l}\text { alberiquer, }-a / \\
\text { alberiqueny, }-a\end{array}$ \\
\hline Bolvir (Cat) & & cerdans & & bolvirenc \\
\hline Campello, el (Val) & & campelleros & & campeller, $-a$ \\
\hline Capdepera (Bal) & & capdeperins & & gabellí, -ina \\
\hline Casinos (Val) & & casineros & & casiner, $-a$ \\
\hline Castell de Vilamalefa, el (Val) & & castilleros & & casteller, $-a$ \\
\hline Castelló de Farfanya (Cat) & & catellonins (poco usado) & & castelloní, -ina \\
\hline Caudete de las Fuentes (Val) & & caudeteños & & caudetenc, $-a$ \\
\hline Cocentaina (Val) & & cocentainer & & $\begin{array}{l}\text { contestà, -ana / } \\
\text { cocentainer, }-a\end{array}$ \\
\hline Crevillent (Val) & & clevillenteros & & crevillentí, - $a$ \\
\hline Dolores (Val) & & majaero & & dolorenc, $-a$ \\
\hline Dosaigües (Val) & & dosagüeros & & dosaigüer, $-a$ \\
\hline Godelleta (Val) & & golletanos & & godelletà, -ana \\
\hline Granada, la (Penedès) (Cat) & & granadins & & granadenc, $-a$ \\
\hline Marines (Val) & & marineros & & mariner, $-a$ \\
\hline Massalavés (Val) & & $\begin{array}{l}\text { massalavesseros poco } \\
\text { usado }\end{array}$ & & massalavesí, -ina \\
\hline Montuïri (Bal) & & montuïrenc & & $\begin{array}{l}\text { montuïrer, } \\
\text { montuïrenc }\end{array}$ \\
\hline Pinós, el (Val) & & pinoseros & & pinoser, $-a$ \\
\hline Pobla de Benifassà, la (Val) & & pobletans, poblencs & & poblatà, -ana \\
\hline Viladecavalls (Cat) & & trumbaire (es un apodo) & & vilacavallenc, $-a$ \\
\hline Vilar de Canes (Val) & & $\begin{array}{l}\text { gentilicio despectivo } \\
\text { llangostes }\end{array}$ & & vilarenc, vilarenca \\
\hline
\end{tabular}

Tabla 2. Discrepancias en los gentilicios del ALPI respecto a otras publicaciones.

Nuevamente se observan formas alternativas en algunos gentilicios. Los encuestadores del ALPI hacen constar soluciones poco usadas, castellonins y massalavesseros, la última de las cuales ya no es recogida por ON. Cabe destacar que, especialmente en el País Valenciano, abundan mucho más las formas de masculino en -er(o)s, mientras que las formas actuales se inclinan por las soluciones normativas, e incluso las recomiendan, indicando para gentilicios como calero o ampollero, "forma molt popular no apta per a un registre formal o en la llengua estàndard". EI ALPI también incorpora denominaciones despectivas, cosa que constituye una nueva 
muestra de que el origen de las denominaciones surge de las poblaciones colindantes y no de los propios habitantes.

c) Los gentilicios del DCVB discrepan de los propuestos por los repertorios actuales (Tabla 3):

\begin{tabular}{|c|c|c|c|c|}
\hline Localidad & $\mathrm{CC}$ & $A L P I$ & $D C V B$ & ON \\
\hline Agramunt (Cat) & & & agramuntès & agramuntí, -ina \\
\hline Altafulla (Cat) & & & $\begin{array}{l}\text { altafullenc / altafullí } \\
\text { (Aladern Diccionari) }\end{array}$ & altafullenc, - $a$ \\
\hline Andratx (Bal) & & & andratxol / andritxol & andritxol, $-a$ \\
\hline Arenys de Mar (Cat) & & & $\begin{array}{l}\text { aranyoní (natural d'Arenys, } \\
\text { Aguiló Dicc.) }\end{array}$ & arenyenc, $-a$ \\
\hline Artà (Bal) & & & artanenc / artaner & artanenc, $-a$ \\
\hline Bisbal de Falset, la (Cat) & & & bisbalenc, bisbalí & bisbalenc, $-a$ \\
\hline $\begin{array}{l}\text { Bonrepòs i Mirambell } \\
\text { (Val) }\end{array}$ & & & mirambellà & bonreposí, -ina \\
\hline Borriana (Val) & & & borrianer, borrianenc & borrianenc, $-a$ \\
\hline Granollers (Cat) & & & granollerí, granollessenc & granollerí, -ina \\
\hline Novelda (Val) & & & noveldenc & novelder, $-a$ \\
\hline Pedreguer (Val) & & & pedreguero & pedreguerí, -ina \\
\hline $\begin{array}{l}\text { Sanet i els Negrals / de la } \\
\text { Rectoria (Val) }\end{array}$ & & & sanetenc, negralí & saneter, $-a$ \\
\hline Sant Feliu de Guíxols (Cat) & & & santfeliuenc & $\begin{array}{l}\text { guixolenc, - } a \text {; feliuà, } \\
\text {-ana; feliuenc, - } a \text {; } \\
\text { santfeliuenc, }-a\end{array}$ \\
\hline Santa Margalida (Bal) & & & santamargalider & margalidà, -ana \\
\hline Torroella de Montgrí (Cat) & & & torroellenc, torroellès & montgrí, torrellenc \\
\hline Vilavella, la (Val) & & & vilavellà & vilaveller, $-a$ \\
\hline
\end{tabular}

Tabla 3. Discrepancias en los gentilicios del DCVB respecto a otras publicaciones.

Las discrepancias entre los dos repertorios tienen que ver con el uso de los sufijos en los gentilicios, la aparición de formas alternativas o la marca -o de alguna forma masculina.

No hay muchos gentilicios recogidos en la zona de Andorra y de Aragón. Se constata solo la discrepancia, en Benavarre, entre benavarrí (CC) y benavarrès (ON).

\section{Los gentilicios, su sufijación y el área geográfica de aparición}

La distribución aleatoria de los sufijos en los topónimos confirma la opinión de Cabré (1994: 55) según la cual su aparición no depende ni de las características 
fonológicas de la base ni de la tipología del topónimo que actúa como base nominal. Y corrobora también que los topónimos acabados en vocal acentuada, como indicaba, no seleccionan formas sufijadas tónicas (-í o- à). La hipótesis de Moll (1991: 373, 370) que considera que el sufijo -er aparece en topónimos que no tienen e tónica, también se cumple, aunque -er puede adherirse a una base terminada en vocal tónica, que presenta, sin embargo, una -n subyacente (Fondó de les Neus, fondon+er, Polinyà, polinyan+er); pero los criterios de tonicidad y de la existencia de $-n$ subyacente también son válidos para adjuntar el sufijo -enc (Betxí betxin+enc, Teià, teian+enc).

Por otro lado, se observan diversos ejemplos de gentilicios que incorporan, en su formación, una concatenación de sufijos; se trata, por ejemplo, de 'xertolí, que designa a los habitantes tanto de Xert (en Castellón) como de Xerta (en Tarragona), y cuya estructura es la siguiente: xert+ol+í; o los de la Roca del Vallès (roqu+er+ol), de Tremp (tremp+ol+i) o de Montferrer (montferr+iny+ol), Roses (rostet+à, DCVB, pero ON rosinc), cuyos sufijos se encuentran, en proporciones variables, en otros gentilicios.

Si las características de la base no explican el uso de un determinado sufijo, el examen desde una perspectiva histórica quizá podría justificar, en algunos casos, su distribución geográfica. A continuación, se ofrece un breve perfil etimológico de cada uno de los sufijos citados en este trabajo (cf. también Coromines (1991), Moll (1995), Moran (1995) y Casanova (2001)), y se indica, clasificándolo en sufijos mayoritarios y minoritarios, su área geográfica de aparición.

\subsection{Los sufijos mayoritarios}

La distribución de los 1841 gentilicios que se ha expuesto en $\S 4$ permite determinar de manera general cuáles son los sufijos más usados (Gráfico 1) en todo el dominio de habla catalana: 


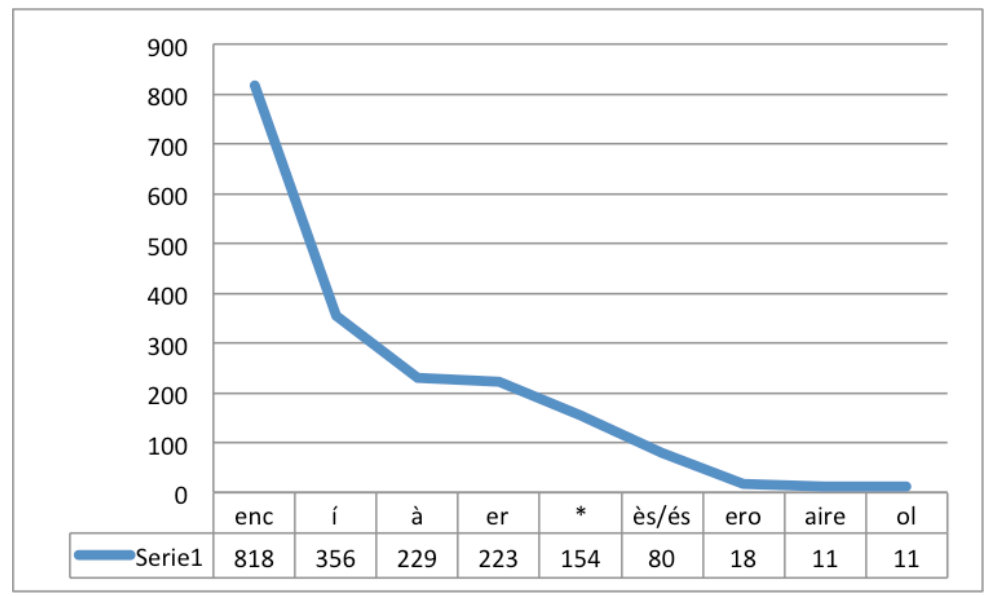

Gráfico 1. Clasificación de los sufijos de los gentilicios según su uso. ${ }^{10}$

Como ya se ha indicado, las localidades cuyos gentilicios se han analizado se distribuyen como sigue: 924 de Cataluña, 71 de las Baleares, 202 de la Cataluña del Norte, 547 de Valencia, 7 de Andorra y 63 de Aragón. Si se desglosan los gentilicios según los territorios indicados, se observa que la preponderancia de sufijos varía en función de las áreas, hecho que se aprecia más claramente cuando se analizan algunos sufijos minoritarios. La distribución geográfica de los gentilicios mayoritarios es la siguiente (Gráfico 2):

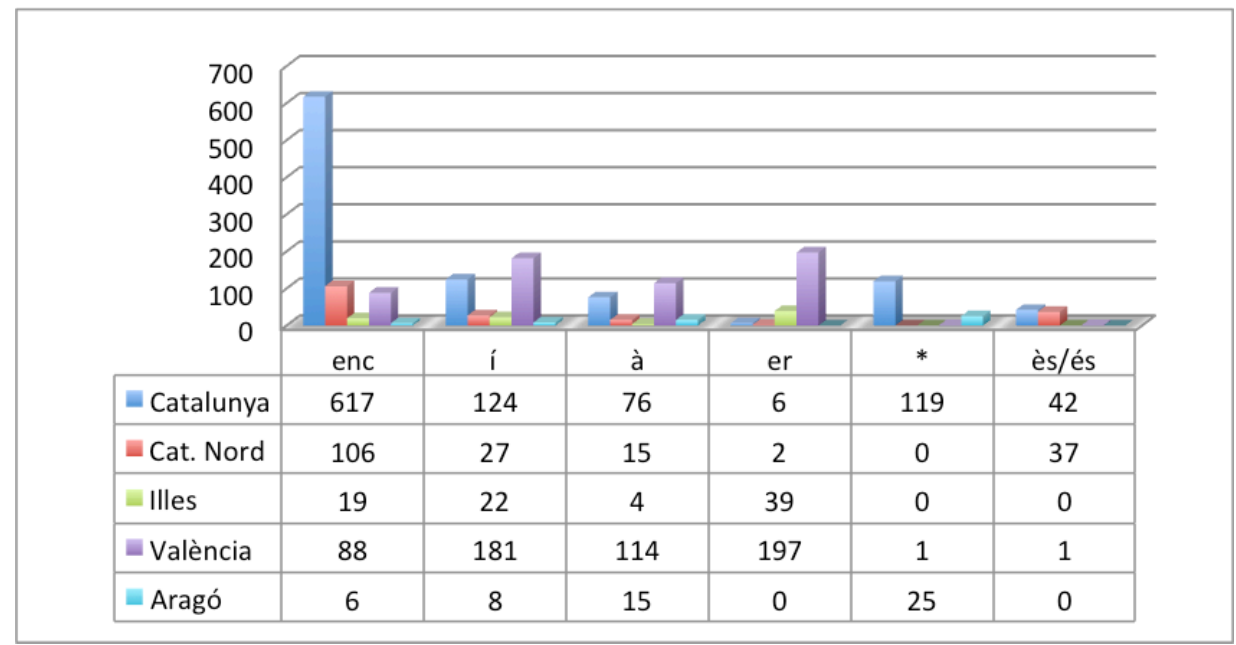

Gráfico 2. Distribución geográfica de los sufijos mayoritarios.

\footnotetext{
${ }^{10}$ La casilla con el asterisco indica la inexistencia de gentilicio en esas localidades y por lo tanto el uso de la forma del genitivo.
} 
Para una distribución más representativa, se ha calculado el porcentaje con relación al número total de localidades de cada área que se han examinado (Gráfico 3):

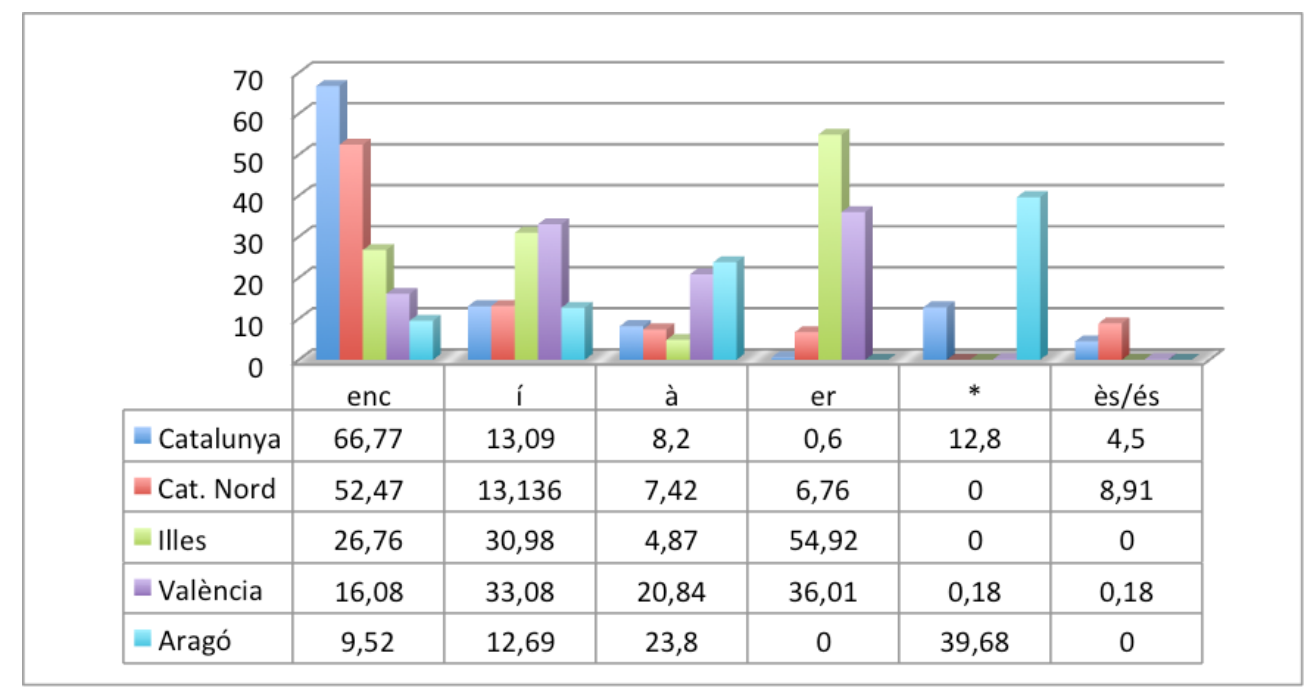

Gráfico 3. Distribución geográfica de los sufijos mayoritarios con relación al número de las localidades de cada área.

La etimología de los sufijos mayoritarios se indica a continuación:

1. -enc (818): ${ }^{11}$ de origen germánico ( ${ }^{*}$-ink), es uno de los sufijos más extendidos. Sin embargo, se observa un contraste entre la gran presencia de este gentilicio y las relativas escasas muestras de léxico germánico en las tierras de lengua catalana. Precisamente su origen parece justificar su aparición mayoritaria en grandes zonas de Cataluña y de la Cataluña del Norte.

2. -í (356): de origen árabe $(-\hat{\imath},-1 \hat{y} a$,$) , quizá con influencia del latín -inu (cf. Sanchis$ 1980: 88). Es particularmente frecuente en el País Valenciano y en las Islas Baleares, cosa que podría explicarse por factores históricos como la Reconquista.

3. -à (229): parece que este gentilicio con -á tónica es el resultado de la evolución del sufijo latino -anu. Se halla ampliamente representado en Valencia y en algunas localidades aragonesas, y cuenta con una presencia inferior en el resto del territorio.

4. -er (223): este gentilicio procede de -ariu. Su campo de difusión es el País Valenciano y las Islas Baleares; en Cataluña, la Cataluña del Norte y Aragón su

\footnotetext{
${ }^{11}$ La cifra entre paréntesis indica el número de localidades que presentan un gentilicio con el sufijo en cuestión.
} 
presencia es minoritaria o inexistente. Se asocia, obviamente, con el sufijo -er(o), que se comentará más adelante.

5. -ès/és (80): el caso de la acentuación grave o no de este sufijo, procedente de ense, y muy usado para formar adjetivos de procedencia o de residencia, responde a la división de la lengua catalana en las áreas oriental y occidental. Esta partición, que no es absoluta en todos los aspectos lingüísticos, es motivada por un criterio fonético. El sufijo predomina particularmente en la Cataluña del Norte y en Cataluña, en cuya franja occidental se registra -ès por convención ortográfica, aunque la pronunciación real es -és. En Balear seria -[ás], pero no hay ninguna muestra del uso de este sufijo.

Los tres sufijos siguientes no son mayoritarios, pero aparecen en más de diez gentilicios, cifra con la cual se inicia el cómputo de los sufijos minoritarios o únicos.

6. -ero (18) (Mapa 2):12 sufijo proveniente de -er, al parecer los topónimos terminados en - $O$ deben esa $o$ átona a la influencia castellana, aunque no todos. La prescripción normativa es eliminar esa vocal final, originando resultados, en los lugares donde se usa, sin tradición alguna. Casanova (2001) cree que procede del aragonés -ero, que servía para formar adjetivos peyorativos en Valencia y en las Baleares desde el siglo XVI. A su parecer el sufijo -er es el resultado de la catalanización de -ero.

7. - aire (12) (Mapa 3): ${ }^{13}$ excepto en un solo caso (Preixens (Lérida) preixenaire), -aire se encuentra en la Cataluña del Norte. Este sufijo tiene origen occitano (-ator) y la prueba es que se halla prácticamente solo en el área citada.

\footnotetext{
${ }^{12}$ Se encuentra en Cat[aluña] (5): Deltebre cavero (ON, pero también deltebrenc y caver); Roquetes roquetero (ON, pero también roquetenc); Sant Jaume d'Enveja santjaumero (ON, pero también santajumenc y santjaumer); I'Ametlla de Mar calero (ALPI y ON, pero también ON caler); I'Ampolla ampollero (ON, pero también ampollenc y ampoller); Bal[eares] (1): Esporles vilero (CC, pero también CC y ON esporleri); Val[encia] (12): Anna anneros (CC, pero ON anner); Ademús ademuceros (ALPI, pero ON ademusser); el Campello campelleros (ALPI, pero ON campeller); Casinos casineros (ALPI, pero ON casiner); el Castell de Vilamalefa castilleros (ALPI, pero ON casteller); Dosaigües dosagüeros (ALPI, pero ON dosaigüer); Marines marineros ( $A L P I$, pero ON mariner); el Pinós pinoseros ( $A L P I$, pero ON pinoser); Beniopa benioperos (ALPI); Crevillent clevillentero (ALPI, pero ON crevillentî); Massalavés massalavesseros poco usado ( $A L P I$, pero ON massalavesi); Pedreguer pedreguero (DCVB, pero ON pedregueri).

${ }^{13}$ Se encuentra en Cat (1): Preixens preixenaire (ON); C[ataluña] N[orte] (11): Fillols fillolaire (ON); Molig molitjaire (ON); Santa Maria de la Mar santmariaire (SO); Mosset mossetaire (DCVB y ON mossataire [sic], pero también ON mossetà, mossetenc); Canet de Rosselló canetaire (DCVB y ON, pero también canetenc, nazarienc); Castell de Vernet castellaire (ON, pero también castellenc); Mentet mentetaire (ON, pero también mentetenc); Conat conataire (ON, pero también conatès); Noedes noedaire (DCVB y $\mathrm{ON}$, pero también ON noedí y noedès); Vernet vernetaire (DCVB y ON, pero también ON vernetenc); Campome campomaire (ON, pero también campomenc). Excepto en un solo caso, el sufijo -aire se encuentra en la Cataluña del Norte.
} 
8. -ol (11) (Mapa 4): ${ }^{14}$ El sufijo -ol, pronunciado siempre con $o$ abierta, procede del latín vulgar -olu, clásico -eolu, y tiene un carácter diminutivo; se encuentra tanto en Cataluña como en Valencia, las Islas Baleares, la Cataluña del Norte y Aragón, pero en un número muy reducido. Es interesante el cambio que tiene lugar en la base de algunos gentilicios acabados en $s$ que adoptan la $r$ (Arnes arnerol; Caseres caserol), que podría explicarse por rotacismo.

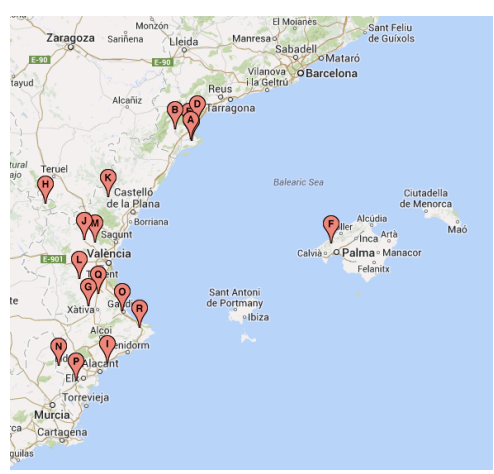

Mapa 2. Sufijo -ero.

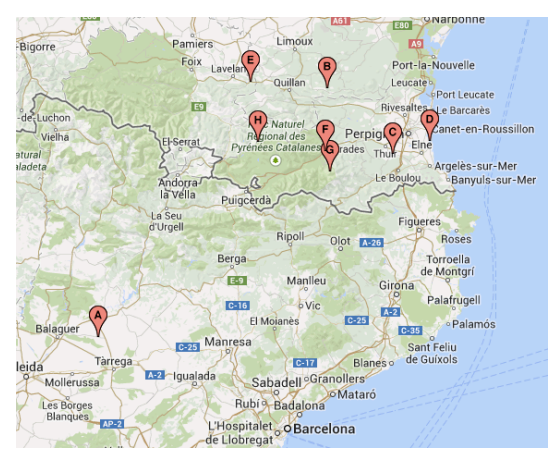

Mapa 3. Sufijo -aire.

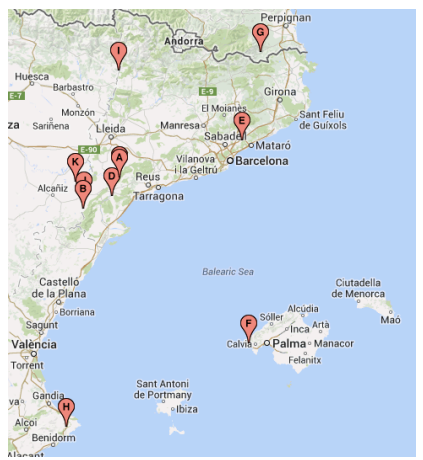

Mapa 4. Sufijo -ol.

\subsection{Los sufijos minoritarios o únicos}

Se indica a continuación la distribución geográfica de los sufijos menos frecuentes:

\footnotetext{
${ }^{14}$ Se encuentra en Cat (6): la Figuera figuerol (CC, pero DCVB y ON figuerenc); Arnes arnerol (ON); Cabacés cabasserol (ON); Caseres caserol (ON); Ginestar ginestarol (ON); la Roca del Vallès roquerol (SO); Bal (1): Andratx andritxol (DCVB y ON, pero también DCVB andratxol); CN (1): Montferrer montferrinyol (ON); Val (1): Senija senijol (DCVB y ON); Ar[agón] (3): Areny de Noguera arenyol (ON); Arenys de Lledó arenyol (ON); Favara de Matarranya favarol (ON). El sufijo -ol se encuentra tanto en Cataluña como en Valencia, las Islas Baleares, la Cataluña del Norte y Aragón.
} 


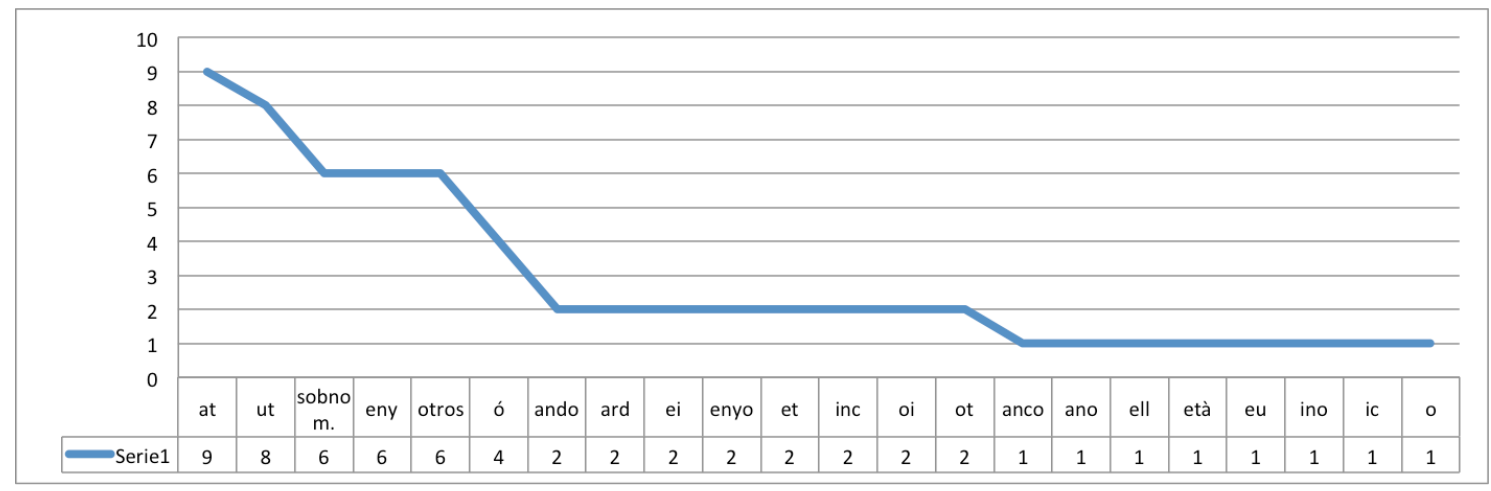

Gráfico 4. Distribución geográfica de los sufijos minoritarios.

9. -at: El sufijo se encuentra sólo en poblaciones de la Cataluña del Norte (9): Aiguatèbia i Talau aiguatebiat (ON, pero también d'Aiguatèbia i Talau y Talauenc); Fontpedrosa fontpedrosat (DCVB y ON); Font-rabiosa font-rabiosat (DCVB y ON); Jújols jujolat (ON); la Llaguna llagunat (ON); Ralleu rallevat (ON); Toès i Entrevalls toesat $(\mathrm{ON})$; Canavelles canavellat (ON, pero también canavellenc); Planès planesat (ON, pero también planesenc). Como se indica en ON, la forma femenina es la solución sonora ada. Según Moran (1995), su origen podría ser -attu y no -atu, ya que las formas occitanas roergat (Roergue) y auvergnat (Auvergne) estarían formadas a partir del primer sufijo.

10. -ut (8): Este sufijo, de carácter intensivo, ubicado mayoritariamente en topónimos del País Valenciano, tiene un origen jocoso, a partir de defectos humanos (cf. orellut). Cat (1): Fatarella fatarellut (ON, DCVB); Val (7): Castalla castallut (ON, CC); Benicàssim benicassut; Cabanes cabanyut, pero DCVB: cabanenc; Benimantell benimantellut (ON); la Canyada canyut (ON); Ibi iberut, pero DCVB ibier; Senyera senyerut (ON); Biar biarut (ON, CC, $A L P I)$, pero también ON biarenc.

El grupo "otros" (7), está formado por denominaciones que pueden considerarse paragentilicios (véase Aragonès 1999): Cat (4): Rialp pallaresos (ALPI); València d'Àneu valencians pallaresos (ALPI); Bolvir cerdans (ALPI, pero ON bolvirenc); Senterada muntayesos de Senterada (ALPI, pero DCVB y ON senteradí); Sant Llorenç de Morunys 
piteu $^{15}$ (ON, pero también Ilorencí y santllorencí); CN (1): Prada gent de Conflent (ON, pero también pradenc); Val (1): Benialí mallorquins de Gallinera (ALPI).

Apodos (6): Cat: Sant Bartomeu del Grau santbartomeus (solo humorísticamente) $(A L P I)$; Viladecavalls trumbaire (es un apodo) ( $A L P I$, pero ON vilacavallenc); Organyà ganxos (nombre jocoso que les dan los de los pueblos vecinos) (ALPI), pero organyès $(\mathrm{ON})$, organyanès (CC)); Aspa rabosetes (ALPI); Val: Vilar de Canes gentilicio despectivo llangostes $(A L P I)$, pero ON: vilarenc; Dolores majaero ${ }^{16}(A L P I)$, pero ON dolorenc.

11. -eny (6): aunque procede del latín -innu, lo encontramos sobre todo en adaptaciones del castellano: madrileño (madrileny), lo que hace suponer a Moran (1995) y a Giner (ap. Casanova 2001) este origen. Bal (1): Porto Cristo porteny (ON); Val (5): Alzira alzireny (ON, DCVB, pero también alzirenc (ON); Algar de Palància algareny (ON, pero también algarenc); Almussafes almussafeny (ON, pero también almussafenc), Russafa russafeny (DCVB, pero también russafer); Alberic alberiqueny ( $D C V B$ y ON, pero también SO alberiquer). Se halla mayoritariamente en topónimos valencianos, aunque se encuentra también en una localidad de Mallorca.

12. -ó (4): Esta terminación en -o tónica (del latín -one) es un intensivo que en catalán tiene un valor diminutivo y forma muy pocos gentilicios que se hallan distribuidos entre Cataluña, Baleares, Valencia y Aragón. Cat (1): Sant Climent de Llobregat (ON: climentó, pero también climentec); Bal (1): Búger bugerró (ON); Val (1): Càlig calijó (ON); $\operatorname{Ar}(1)$ : el Campell elcampelló (ON).

13. -ando (2): es un sufijo muy raro y solo aparece en dos casos. Bal (1): Maria de la Salut mariando (ON, pero también marier); Val (1): Benicarló benicarlando. Coromines (1995, s.v. Carles i Benicarló) no considera benicarlando un apodo, sino un gentilicio constituido por el sufijo -ando, el cual también se halla en el de una localidad de las Islas Baleares. Termina, como otros sufijos gentilicios, en una - $o$ átona.

14. - ard (2): originario del germánico -hart (cf. Moll 1991: 188), ha pasado a formar los gentilicios de la zona a partir de la influencia francesa, teniendo en cuenta que solo aparece en los de dos topónimos de la Cataluña del Norte (CN): Sallagosa

\footnotetext{
${ }^{15}$ Se ha originado por la antigua denominación de la localidad, Sant Llorenç dels Piteus.

${ }^{16}$ La forma majaeros se justifica porque a la localidad se la conoció, e incluso aún hoy, como 'la Majá'.
} 
sallagosard (ON, DCVB apud Griera (Atlas); Cànoes canoard (ON, pero también canoenc).

15. -enyo: Val (2) Caudete caudeteños ( $A L P I$, pero SO caudetenc), Rafelguaraf rafelguerenyo (DCVB, pero ON rafeguarafí). Es el sufijo -eny, de -ignu, con la o final, muy probablemente de origen castellano. El municipio de Caudete pertenece a la zona castellano hablante de Valencia, pero no así la localidad alicantina de Rafelguaraf.

16. -et (2): Sufijo diminutivo derivado de -ittu, tiene muy poca rentabilidad para formar gentilicios, que aparecen en topónimos localizados en la zona septentrional. Cat (1): Ivars de Noguera ivarset (ON); CN (1) Vilallonga de Salanca vilallonguet (ON).

17. -inc: Cat (2): Rabós: rabosinc (ON, pero DCVB rabosenc); Roses rosinc (ON, pero DCVB 'rosetà'). No se considera sufijo (cf. Cabré 1994: 105), y Moll (1991, § 406) cree, basándose en las formas nominales donde aparece (esquellinc, esquellerinc), que se trata de una terminación basada en una onomatopeya similar a dring-dring, dingding.

18. -ot: se encuentra en dos localidades de la $\mathrm{CN}$ : Orellà orellot (ON, pero también orellanenc); Salses salsirot (DCVB, pero ON salsairot). Procedente de -ottu, Moll $(1995, \S 426)$ señala que este sufijo en catalán norte-oriental tiene un significado diminutivo peyorativo, que es el que debe poseer en los gentilicios citados, mientras que en el territorio catalán restante tiene un valor aumentativo con un matiz despectivo.

19. -oi (2): Cat (1): Sant Quintí de Mediona quintinoi (ON, pero también quintinenc); CN (1): Agostrina y Vilanova de les Escaldes agostrinoi (ON, pero también angostrinès, gent d'Agostrina i Vilanova de les Escaldes y vilanoví). Situado en el área septentrional el sufijo -oi, de carácter muy minoritario para formar diminutivos, tiene un carácter valorativo.

20. -anco: Cat (1) Flix flixanco (DCVB, apud Griera, pero ON flixenc). Corominas (1991, s.v. Flix) considera que el gentilicio tiene origen mozárabe, ya que se halla en una zona que conservó bastantes restos mozárabes. Sin embargo, Griera lo recoge como "adj. seriós alguns o bé altres com a 'motiu'” (VII, 9), lo que parece más cercano a la realidad, puesto que no está catalogado como sufijo (cf. Cabré 1994: 105). 
21. -ano: Val (1): Godelleta golletanos (ALPI, ${ }^{17}$ pero ON godelletano). Este gentilicio de la localidad no valenciano hablante de Godelleta está formado por el sufijo -á(n) seguido de la -o final de origen castellano.

22. -ei: Bal (1): Galilea galilei (DCVB apud. Aguiló). Esta forma sólo aparece documentada en el DCVB.

23. -ell: Val (1): Pinet pinetell (ON). Procedente de 'pi', el gentilicio ya contiene un sufijo diminutivo y la denominación se forma añadiendo otro sufijo procedente del latín -ellu, de valor igualmente diminutivo.

24. -eu: Cat (1): Alcanar canareu (ON). Se trata de un gentilicio singular de carácter popular, según Coromines (1991, s.v. Alcanar), y muy difundido. Este autor postula una probable forma *canare(s)os, con eliminación de la consonante intervocálica a la cual ha contribuido la disimilación en el plural, que es la forma usada con más frecuencia.

25. -ic: Bal (1): Sóller solleric (ALPI, DCVB y ON). Mientras que Moll (1991: §395) considera que este gentilicio no contiene un verdadero sufijo, sino que procede de la adopción de un topónimo, Solleric, que correspondía a una gran alquería de las montañas de Mallorca, Corominas (1991: s.v. Sóller) cree que este estaría formado por el sufijo gentilicio -í, al que se habría añadido una consonante duplicada, habitual en los arabismos, siguiendo el modelo de alambí / alambi+c.

26. -ino: Val (1): Monforte monfortino (ALPI). Se trata del sufijo -i(n), nuevamente con la vocal final -0 , de origen castellano.

27. $-0: C N(1)$ : Nyer nyerro (ON). No se trata en realidad de un sufijo, sino de una - o de apoyo como la del sustantivo ferro, que aparece en la forma de masculino.

\subsection{La distribución geográfica}

Se muestra a continuación la distribución geográfica de los gentilicios según su sufijo. Se han cartografiado los correspondientes a Cataluña, las Islas Baleares, la Cataluña del Norte y Valencia.

\footnotetext{
${ }^{17}$ Puede que la forma del $A L P I$ se trate de un error de transcripción.
} 
El Mapa 5 muestra la distribución de los sufijos correspondientes a Cataluña. Para no recargar la representación se ha omitido la localización de -enc, el sufijo más numeroso, que ocuparía los espacios en blanco, junto con las localidades que no tienen gentilicio. Las formas con los sufijos en -í (amarillo) y en -à (rojo) se distribuyen a lo largo del territorio, mientras que el sufijo -ès (verde) se sitúa más bien en el norte.

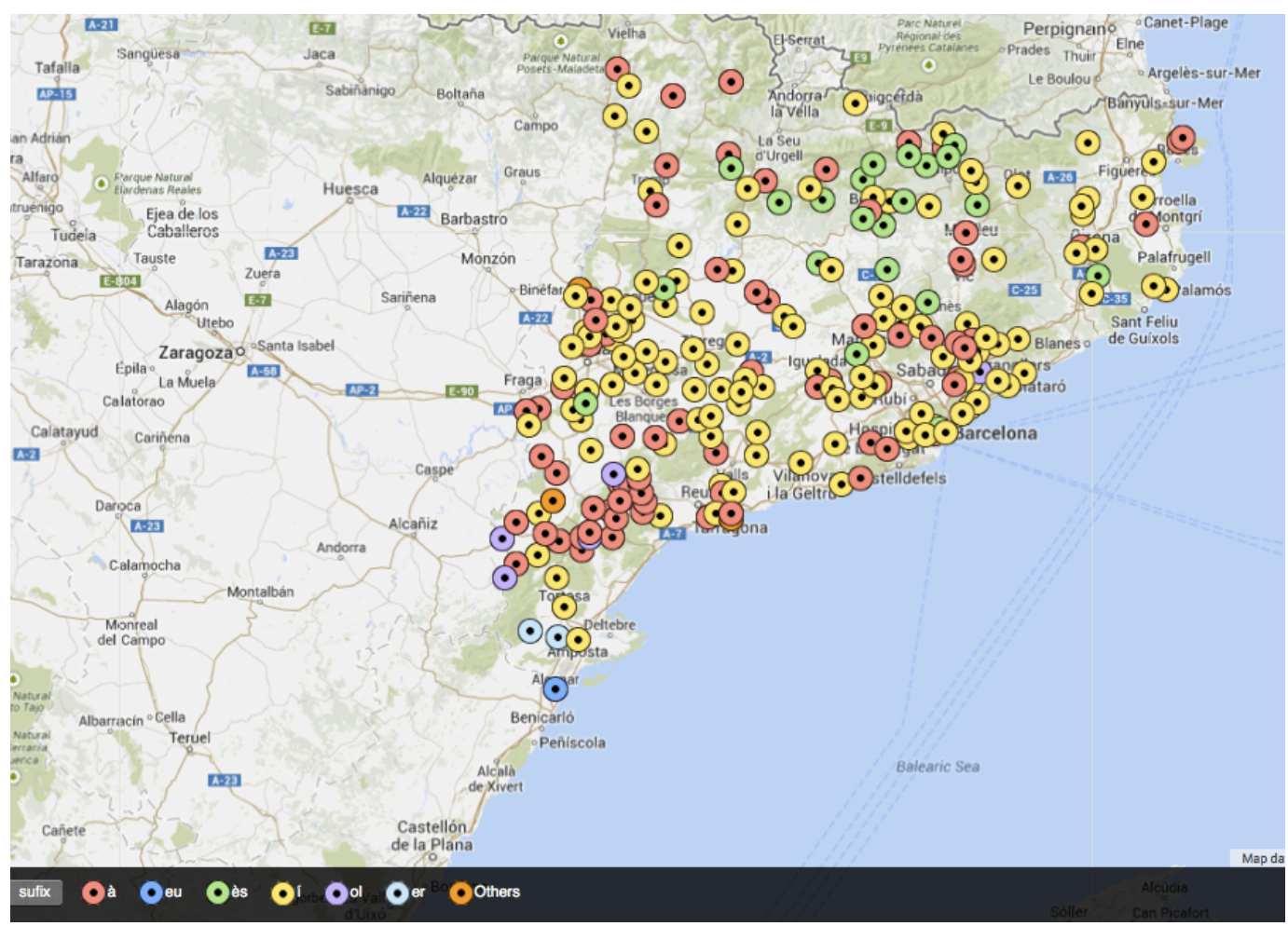

Mapa 5. Distribución de los sufijos en Cataluña.

En el Mapa 6 se representan los sufijos en la Cataluña del Norte, donde proliferan los gentilicios en -enc (naranja), que se distribuyen por todo el territorio. Los acabados en -at (verde) se agrupan en la zona de Formiguera. 


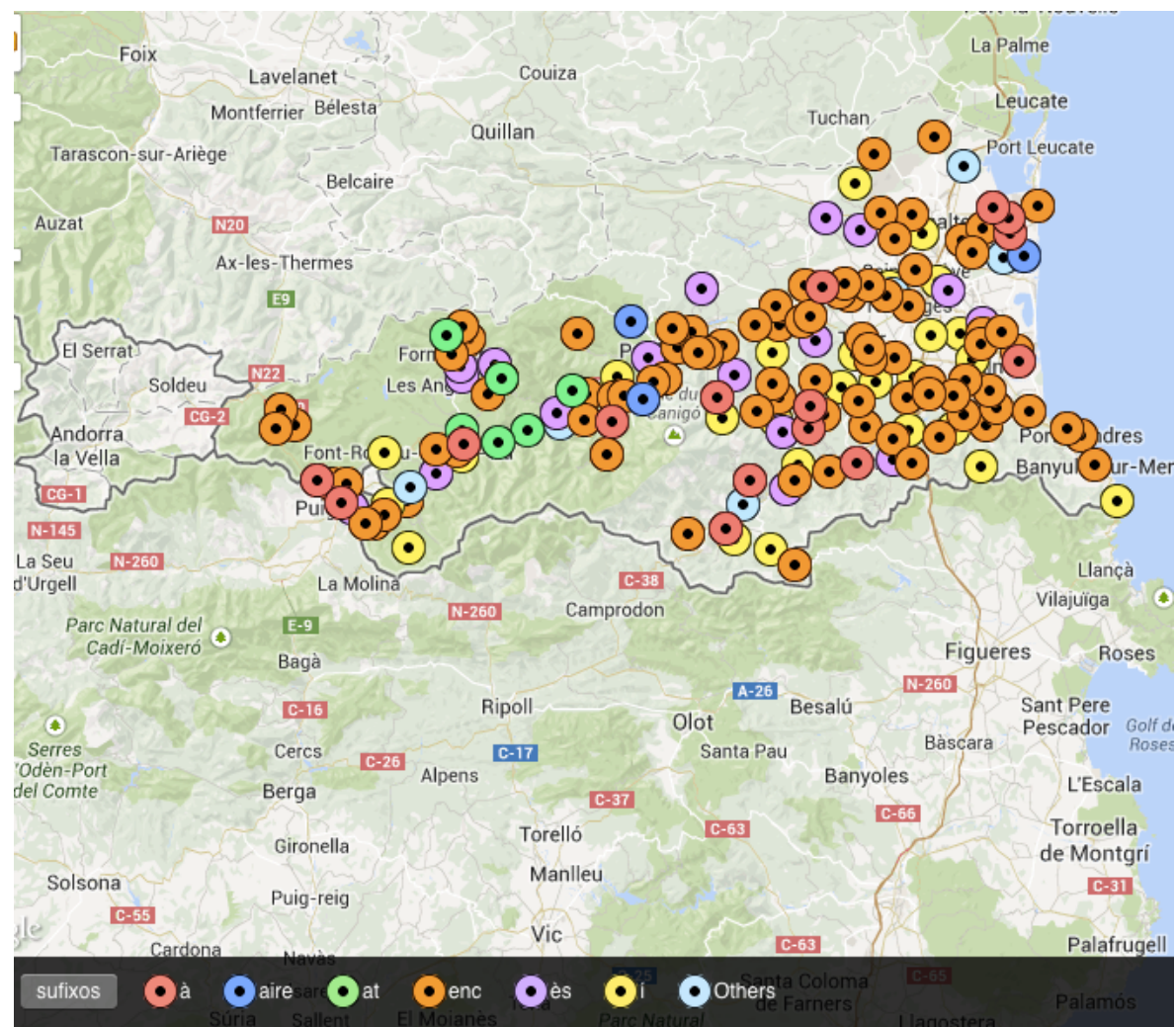

Mapa 6. Distribución de los sufijos en la Cataluña del Norte.

El Mapa 7 muestra la distribución de los sufijos de los gentilicios en las Islas Baleares, donde las formas en -er (verde claro), -enc (naranja) y -í (amarillo) son las dominantes (particularmente en Mallorca). El sufijo -enc (naranja) se halla preferentemente al norte de esta isla.

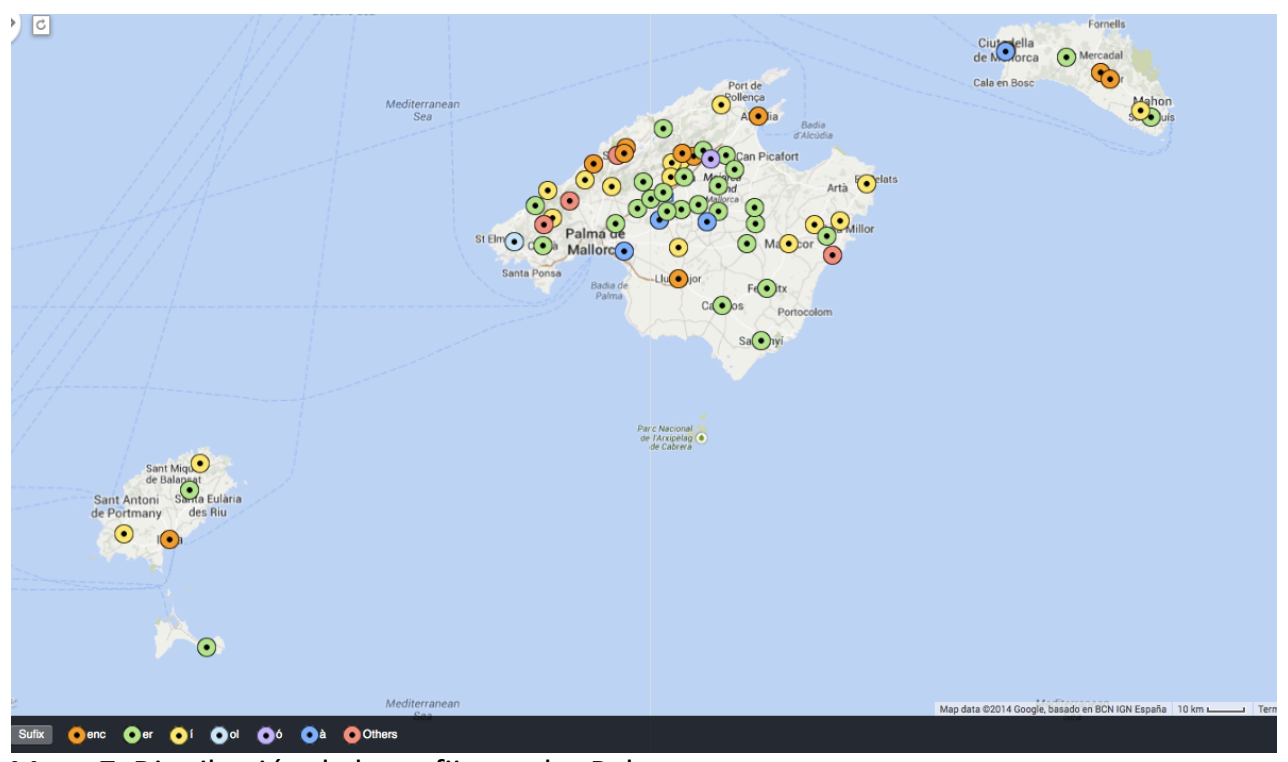

Mapa 7. Distribución de los sufijos en las Baleares. 
El Mapa 8 muestra la distribución de los sufijos de los gentilicios en el País Valenciano, con la exclusión, para una mejor visualización, de los mayoritarios (-er y - 1 ).

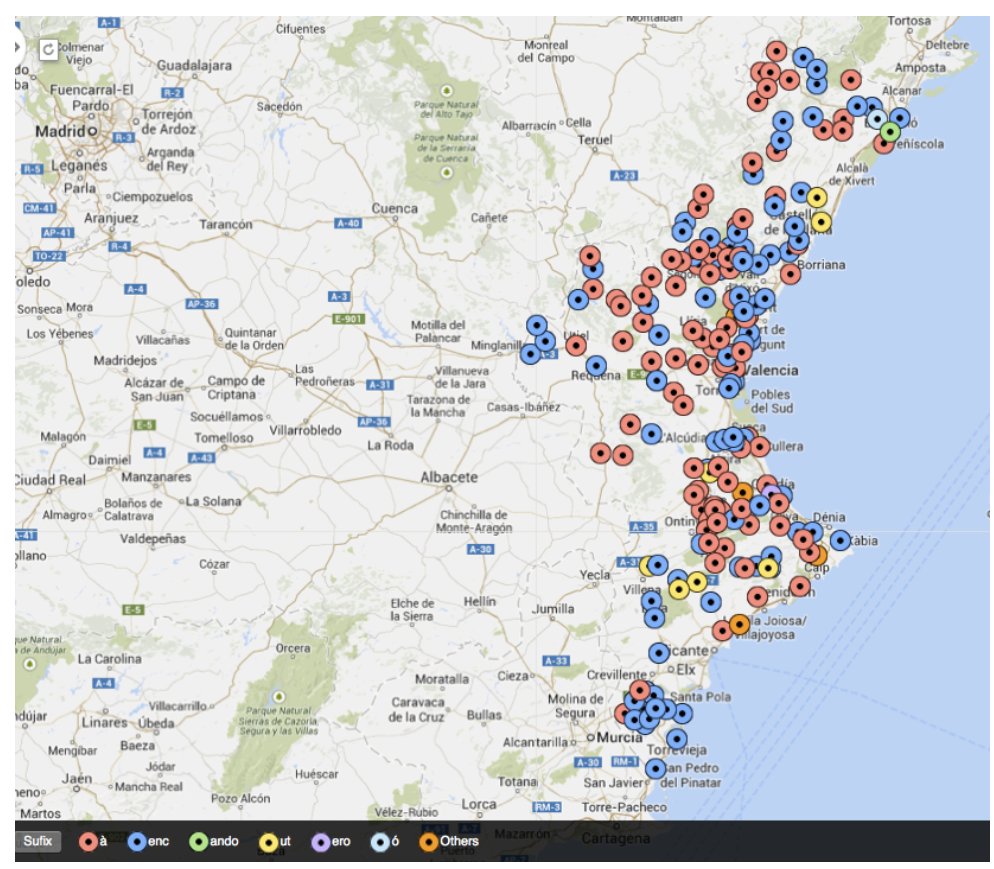

Mapa 8. Distribución de los sufijos en el País Valenciano.

Los Mapas 9 y 10, respectivamente, muestran la distribución de los sufijos mayoritarios en el País Valenciano (-er y -1).

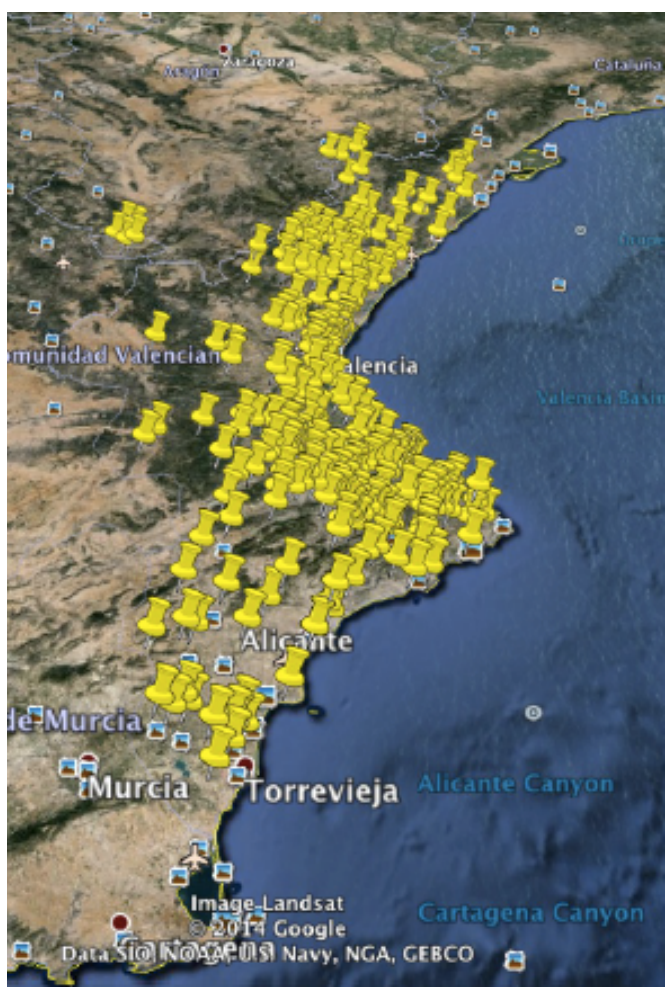

Mapa 9. Distribución del sufijo -er en el PV.

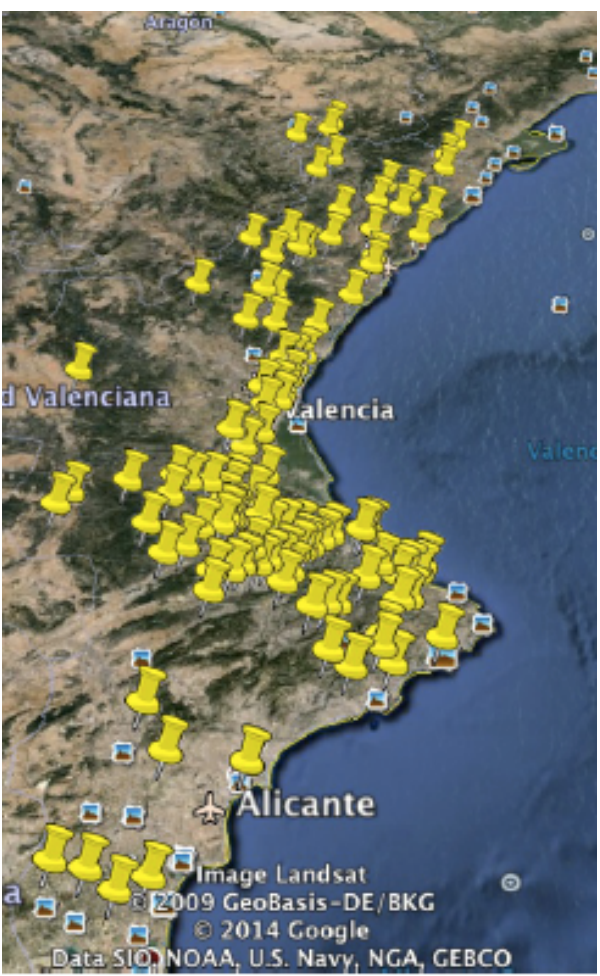

Mapa 10. Distribución del sufijo -í en el PV. 
Finalmente, en el Mapa 11 se representa la distribución de los sufijos de la franja de Aragón.

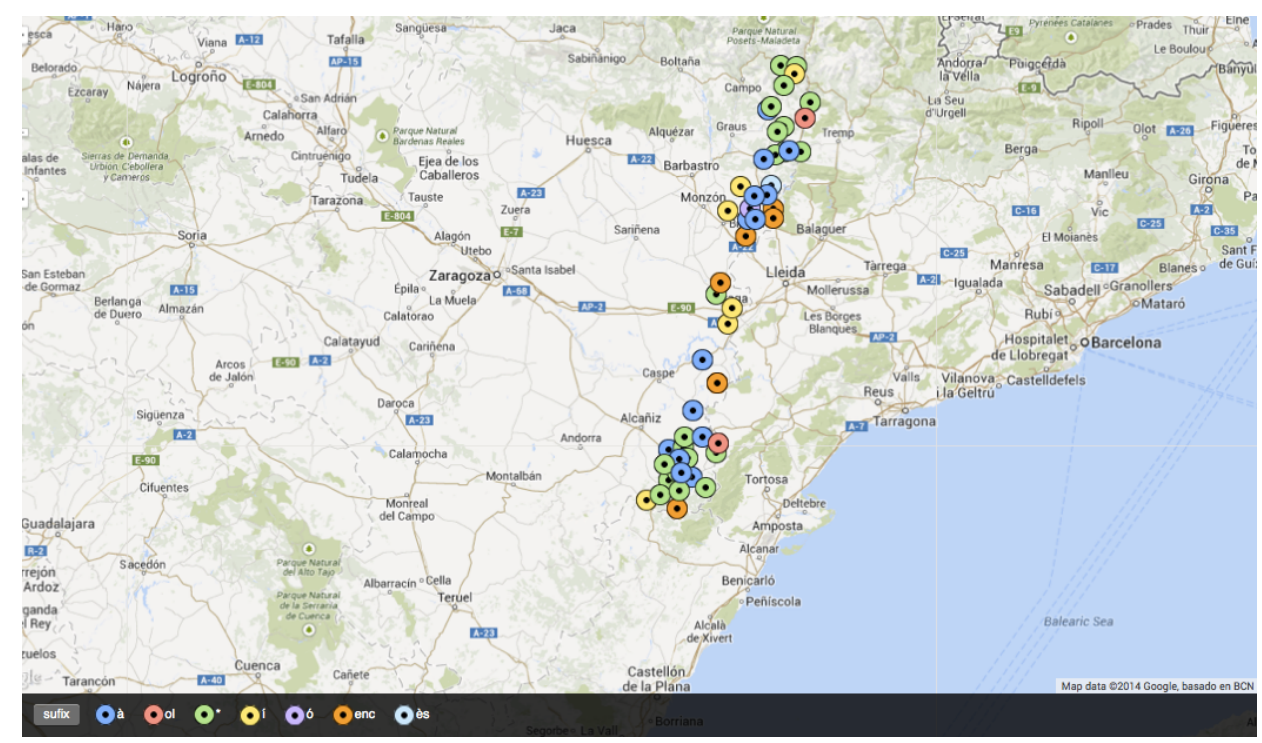

Mapa 11. Distribución de los sufijos en la franja aragonesa.

\section{Conclusiones}

Retomando las preguntas que se habían planteado en $\S 2$ se observa que, en general, se mantienen los gentilicios, aunque se aprecian algunos cambios:

a) Aparecen sufijos (de carácter mayoritario), que substituyen soluciones consideradas antiguas. Ya se ha hecho referencia a algunas ocurrencias de -enc (maonenc o migjornenc). Otros ejemplos se encuentran en las formas alternativas bisbalenc y bisbalí que indicaba el DCVB para la Bisbal d'Empordà y la Bisbal de Falset, que se han reducido a bisbalenc, porque bisbalí (Bover 1996) se cree antiguo. Lo mismo sucede con el gentilicio de la localidad mallorquina de Santa Margalida: santamargalider considerado antiguo, es substituido por margalidà (Bover 1996).

b) Aparecen formas alternativas, como sugieren algunos repertorios recientes (Vinebre, vinebrà y vinebrí o Tivenys, tivenysenc y tivenysà), aunque el segundo solo aparece en la Guia del Parlament (2012), pero no en Bover (1996) ni en la publicación de la Societat d'Onomàstica. Muy probablemente estas formas dobles no aparecieron a la vez, sino que una es más moderna que la otra. Navarro (2000), por ejemplo, indica 
que en el caso de los gentilicios de Bot, botarell y botenc, el segundo parece ser de introducción reciente.

c) Se usan en algunos casos sobrenombres opacos, como gabellí para los habitantes del municipio mallorquín de Capdepera, que parece que ha substituido la forma más transparente capdeperí $(A L P I)$, y que el $D C V B$ ya había constatado: "nom que la gent d'Artà i de Manacor dóna als nadius de Capdepera (Mall). [...] Etim.: incerta. Potser de l'àrab jablí, 'muntanyenc', o derivat de gabella?)". ${ }^{18}$

d) En la Cataluña del Norte, se substituyen progresivamente las formas en -aire, por soluciones alternativas en -enc, que es el sufijo mayoritario del área: Canet del Rosselló canetaire, canetenc, nazarienc; ${ }^{19}$ Vernet vernetaire, vernetenc.

e) Aunque vinculados a los gentilicios, los apodos ${ }^{20}$ (véase Aragonès (1999), que los denomina 'malnoms gentilicis'), de los cuales con frecuencia se desconoce el origen, solo fueron registrados por Alcover y especialmente por el $A L P I$, no suelen constar en los repertorios actuales.

f) Cabe destacar la influencia de la norma en las denominaciones de los habitantes de ciertas localidades. Sufijos con tradición, como los acabados en -ero (véase el Mapa 2), son sancionados como no normativos en la publicación del Parlament y por Bover (1999), hecho que Aragonés (1999) critica en algunos casos, considerando su genuinidad.

g) En este trabajo se han detectado inicialmente 27 terminaciones que, con mayor o menor rentabilidad, pueden formar gentilicios. Aunque deben hacerse reajustes porque la lista incluye elementos no sufijales, el número resultante, 25, discrepa, de Bover (1996), que determinaba 22, y de Soler (1979), que recogía 30, porque también incluía apodos. Los cinco sufijos más usuales son, por orden de mayor a menor frecuencia, -enc, -í, -à, -er, -ès/és. El sufijo -eny (o -eny(o)), que indica Soler (1979: 29) como frecuente, no supera, en los datos analizados, las ocho ocurrencias.

\footnotetext{
${ }^{18}$ Sin embargo, según el Servei d'Assesorament Lingüístic de Capdepera: “Gabellí: L'etimologia és incerta i potser que provengui de l'àrab jabli 'muntanyenc'. L'etimologia popular, en canvi, ho relacionaria amb gabella 'impost' i gavell 'paquet' o refugi de la gent que vivia dispersa per les contrades de Capdepera i que s'arreplegava dins el castell en cas de perill".

19 'Nazarienc' (véase Bover (1996) y Guia de gentilicis (2012); no aparece en la ON) se refiere al gentilicio correspondiente Sant Nazari de Rosselló, que se unió a Canet de Rosselló en 1975, aunque se volvió a separar en 1984.

${ }^{20}$ Véase también los trabajos de Moreu-Rey (1981), Navarro (2000) y Bertran (2003) relacionados con los apodos.
} 
h) La lista inicial de sufijos se ha reducido a 25 porque se ha eliminado, por un lado, la terminación átona -o (nyerro) y, por otro, la forma -anco (flixanco), cuyo gentilicio parece ser más bien un apodo.

i) Aunque el uso de los sufijos puede explicarse por las características formales de su base, es cierto que en su distribución existe una clara relación entre área geográfica y frecuencia de aparición. Este hecho sucede claramente en los gentilicios de la Cataluña del Norte (aire, -at, -ard y -ot). Por otro lado, la presencia de -enc y de ès al norte y de -í y -er al sur, conociendo su origen, en especial de los dos primeros, ofrece también una información significativa. La adición de la vocal final -o a algunos sufijos es bastante usual, especialmente en la zona sur de Cataluña, Valencia y las Islas Baleares (-ero, -ando, -enyo, -ano, -ino), cosa que puede responder en algunos casos a influencia castellana.

j) Algunos gentilicios adoptan sufijos minoritarios que suelen tener carácter valorativo, en especial diminutivo (-ol, -ó, -et, -oi, -ell) y en algún caso despectivo (-ut), hecho que podría vincular originariamente estas soluciones con los apodos.

k) Otros gentilicios presentan terminaciones que son en realidad pseudosufijos, por tratarse de elementos unitarios (-inc, -ei, -eu). El sufijo -ic de Sóller puede interpretarse muy probablemente como $-i+c$.

I) Es interesante observar que algunos de los gentilicios minoritarios conviven con formas alternativas que suelen corresponder a soluciones mayoritarias, especialmente -enc, lo que hace suponer que este último sufijo puede convertirse en el futuro en el más usado, implicando la desaparición del alternativo.

m) El uso y la difusión de los gentilicios se hallan sometidos a dos presiones: por un lado, la originaria; es decir, por las denominaciones coloquiales propias de los habitantes de las localidades cercanas que denominaban a los de un lugar de una manera determinada, y que no responde en caso alguno a aspectos relacionados con la normativa; por otro, la presión que ejercen actualmente los gramáticos y lexicógrafos que pretenden crear nuevos gentilicios a partir de los existentes, normalmente los mayoritarios, para que todos las localidades los tengan. Es bien sabido que los gentilicios no existen de manera sistemática en todas las lenguas (cf., por ejemplo, en inglés, la extensión de los regional names). Teniendo la posibilidad de 
formarlos con las perífrasis "de X" o "natural de X", en caso de que las localidades no tengan gentilicio, no se considera su creación una tarea de primera necesidad.

\section{Referencias}

ALPI = NAVARRO TOMÀs, Tomás (1962) Atlas Lingüístico de la Península Ibérica, CSIC: Madrid.

ARAGONÈs, Albert (1999) "Noms i malnoms gentilicis del Baix Ebre i del Montsià", Butlletí Interior de la Societat d'Onomàstica, 79, 12-37.

Beltran I CAlvo, Vicent (2003) "Uns crien la fama i els altres carden la llana. Els pobles de la Marina parlen els uns dels altres: gentilicis i renoms", Societat d'Onomàstica. Butlletí Interior, XCIV, 61-71.

BIOSCA I BAS, Antoni (2010) "Elxans i il-licitans. Història d'un gentilici”, La Rella, 23, 13-21.

BOVER I FONT, August (1996) Diccionari de gentilicis catalans, Barcelona: Edicions 62.

CABRÉ, M. Teresa (1994) A l'entorn de la paraula (II). Lexicologia catalana, València: Publicacions de la Universitat de València.

Casanova HerRero, Emili (2001) "Ullada històrica dels sufixos gentilicis catalans", Societat d'Onomàstica. Butlletí Interior, LXXXIV, 28-42.

COROMINES, Joan (1989-1997) Onomasticon Cataloniae. Els noms de lloc i noms de persona de totes les terres de llengua catalana, Barcelona: Curial Edicions Catalanes.

DCVB = ALCOVER, Antoni M. \& MOLL, Francesc de B. (1962-1968) Diccionari català-valencià-balear, Palma de Mallorca: Moll.

GUIA DE GENTILICIS (2012) Parlament de Catalunya, Servei d'Assesorament lingüístic <https://www.parlament.cat/document/intrade/6281> [acceso el 23 de diciembre de 2020].

MARQUET, Lluís (2009) "Sobre els gentilicis en -eny", Llengua nacional: publicació de l'Associació Llengua Nacional, 67, 29.

MoLL, Francesc de B. (1982) Els llinatges catalans, Mallorca: Moll.

MoLL, Francesc de B. (1991) Gramàtica històrica catalana, Barcelona: Universitat de València [1a ed. castellana: 1952, Madrid].

MoRan I OCERINJAUREgUI, Josep (1995) "Els sufixos per a la formació de gentilicis en català", Estudis d'onomàstica catalana, Barcelona: Publicacions de I'Abadia de Montserrat, 155163.

MOREU-REY, Enric (1981) Renoms, motius, malnoms i noms de casa, Barcelona: Editorial Millà. 
Dialectologia. Special issue, IX (2021), 253-284.

ISSN: 2013-2247

NAVARro, Pere (2000) "Gentilicis, renoms col-lectius i dites tòpiques de la comarca de la Terra Alta", Societat d'Onomàstica. Butlletí Interior, LXXXII, 304-312.

PereA, Maria Pilar (2005) Dades dialectals. Antoni M. Alcover, Palma de Mallorca: Conselleria d'Educació i Cultura. Govern de les Illes Balears, CD-ROM. [Consultable en http://alcover.iec.cat/].

SOLER, Josep M. (1979) Gentilicis dels Països Catalans. Paragentilicis, malnoms i sobrenoms, Barcelona: Millà. 
Anexo 1

Lista de gentilicios que aparecen en los cuadernos de campo de Alcover

\begin{tabular}{|c|c|}
\hline $\begin{array}{l}\text { agustiners, } \\
\text { agostinencs }\end{array}$ & Sant Agustí (Eivissa) \\
\hline alaurenc, $-c a$ & Alai \\
\hline albarquins & $\begin{array}{l}\text { Mateuers (Sant Mateu } \\
\text { d'Aubarca) }\end{array}$ \\
\hline almatretans & Almatret \\
\hline arabinencs & Arabí (Eivissa) \\
\hline artesà & Artesa de Segre \\
\hline aubarquí & Aubarca (Eivissa) \\
\hline baganès & Bagà \\
\hline balaguerí, -ina & Balaguer \\
\hline belianencs & Belianes \\
\hline bellmuntà & Bellmunt \\
\hline bellpuigencs & Bellpuig \\
\hline benassalenc & Benassal \\
\hline benavarrí, -ina & Benavarri \\
\hline benidormer, -ra & Benidorm \\
\hline benisser & Benissa \\
\hline biarut, biaruda & Biar \\
\hline bolullers & Bolulla \\
\hline bonansí, -ina & Bonansa \\
\hline bonasquer & $\begin{array}{l}\text { Bonasca: possessió de } \\
\text { Sineu }\end{array}$ \\
\hline bujarró & Búger \\
\hline calallonguers & Calallonga (Eivissa) \\
\hline $\begin{array}{l}\text { calamunters/es } \\
\text { d'aqueixus } \\
\text { amuns (amunts: } \\
\text { regions altes). Els } \\
\text { d'aquests pobles } \\
\text { se diuen } \\
\text { k[a]l[a]muntés } \\
\text { (calamunters) }\end{array}$ & $\begin{array}{l}\text { els de cap amunt, els de } \\
\text { Corona, Sant Agustí, } \\
\text { Sant Mateu d'Aubarca, } \\
\text { Sant Miquel de } \\
\text { Balansat, Sa Cala, Sant } \\
\text { Vicent, Sant Joan de } \\
\text { Labritja, Sant Josep de } \\
\text { sa Talaia, Sant Antoni } \\
\text { de Portmany / Els } \\
\text { amunts d'Eivissa son: } \\
\text { Sant Joan, Sant Vicent } \\
\text { (Sa Cala), Sant Miquel, } \\
\text { Sant Llorenç, Santa } \\
\text { Eulàlia }\end{array}$ \\
\hline $\begin{array}{l}\text { calers (1922) / } \\
\text { caleros (1909- } \\
1921)\end{array}$ & $\begin{array}{l}\text { Sant Vicent, sa Cala és } \\
\text { una vicaria rural que hi } \\
\text { ha (CC Eivissa) }\end{array}$ \\
\hline calers & sa cala de Sant Vicens \\
\hline
\end{tabular}

\begin{tabular}{|c|c|}
\hline callosí, callosina & Callosa \\
\hline campdevanoler & Campdevànol \\
\hline carlins & Sant Carlos \\
\hline carlinus (carlins) & $\begin{array}{l}\text { Sant Carles de Peralta } \\
\text { (Eivissa) }\end{array}$ \\
\hline $\begin{array}{l}\text { castallut, } \\
\text { castalluda }\end{array}$ & Castalla \\
\hline $\begin{array}{l}\text { castellonenc, - } \\
\text { enca }\end{array}$ & Castelló de la Plana \\
\hline $\begin{array}{l}\text { castellufa / } \\
\text { Castellà }\end{array}$ & Vila-Carlos \\
\hline cerdanyès, -sa & Cerdanya \\
\hline ciutadellenc, -ca & Ciutadella \\
\hline colomí & $\begin{array}{l}\text { Santa Coloma de } \\
\text { Queralt }\end{array}$ \\
\hline conquesos & Conca de Tremp \\
\hline coroners & Santa Agnès de Corona \\
\hline deianenc & Deià (Q. Valldemossa) \\
\hline $\begin{array}{l}\text { els d'Agullana, } \\
\text { els de Darnius, } \\
\text { els de Figueres }\end{array}$ & Agullana, Darnius \\
\hline $\begin{array}{l}\text { elxeros. Els d'Elx } \\
\text { los diuen } \\
\text { "elxeros», pero } \\
\text { ells no s'hi diuen, } \\
\text { se diuen } \\
\text { "ilicitans»; però } \\
\text { això es un mot } \\
\text { erudit. }\end{array}$ & Elx \\
\hline encampadà & Encamp \\
\hline escarters (es) & $\begin{array}{l}\text { (ho diuen en els de la } \\
\text { venda des Bessons, a on } \\
\text { només se fan escarts } \\
\text { (carts) i per això les } \\
\text { diuen escarters) / } \\
\text { Eivissa }\end{array}$ \\
\hline espluguí & Espluga de Francolí \\
\hline esporlerí & Esporles \\
\hline establimenters & $\begin{array}{l}\text { Establiments (Q. } \\
\text { Esporles) }\end{array}$ \\
\hline estanyers & $\begin{array}{l}\text { Sant Ferran de } \\
\text { Formentera. Hi ha els } \\
\text { estanys (es pudent i es } \\
\text { des peix, que pertanyen } \\
\text { a Sant Ferran de }\end{array}$ \\
\hline
\end{tabular}


Dialectologia. Special issue, IX (2021), 253-284.

ISSN: 2013-2247

\begin{tabular}{|c|c|}
\hline & Formentera) Q. Eivissa \\
\hline esterrienc & Esterri d'Àneu \\
\hline falsetà & Falset \\
\hline ferrerienc & Ferreries Q. Alaior \\
\hline figuerol & Figuera, la; Q. Falset \\
\hline fonter & Font d'En Carrós \\
\hline $\begin{array}{l}\text { formenterencs / } \\
\text { formenterer } \\
\text { (1902) } \\
\text { formenter (1901- } \\
\text { 1921) }\end{array}$ & Formentera Q. Eivissa \\
\hline fornassers & $\begin{array}{l}\text { des Furnàs, Sant Rafel } \\
\text { de Forca) (Furnàs és una } \\
\text { terra a on fan molts de } \\
\text { forns de calç }\end{array}$ \\
\hline forneller & Fornells \\
\hline fragatí & Fraga \\
\hline gandià & Gandia \\
\hline garrotxins & Garrotxa \\
\hline gombrenès & $\begin{array}{l}\text { Gombrèn Q. } \\
\text { Campdevànol }\end{array}$ \\
\hline granadellenc & la Granadella \\
\hline igualadins & Igualada \\
\hline isonencs & Isona \\
\hline $\begin{array}{l}\text { joanins } \\
\text { (Santjoanencs) }\end{array}$ & Sant Joan de Labritja \\
\hline jordiers & Sant Jordi \\
\hline josepins & $\begin{array}{l}\text { Sant Josep de sa Talaia / } \\
\text { Eivissa }\end{array}$ \\
\hline Iledonencs & Lledó (CC Navata) \\
\hline lleidatà & Lleida \\
\hline $\begin{array}{l}\text { lletrudier / } \\
\text { Iletrudienc (No } \\
\text { hu diuen gayre) }\end{array}$ & $\begin{array}{l}\text { Santa Lletrudis (Santa } \\
\text { Gertrudis de Fruitera) }\end{array}$ \\
\hline llombardés (es) & Llombards, es \\
\hline $\begin{array}{l}\text { Ilorencins (1909- } \\
\text { 1921) / Ilorencers } \\
\text { (1922) }\end{array}$ & Sant Llorenç de Balàfia \\
\hline $\begin{array}{l}\text { lluïssers / } \\
\text { Santlluïssers }\end{array}$ & $\begin{array}{l}\text { als de Sant Lluís los } \\
\text { diuen: Iluïssers i } \\
\text { Santlluïssers / Menorca }\end{array}$ \\
\hline mallorquins & $\begin{array}{l}\text { ho diuen als nadius de } \\
\text { la Vall de Gallinera / Q. } \\
\text { Alpatró }\end{array}$ \\
\hline manacorer & $\begin{array}{l}\text { Manacor Q. Vilafranca } \\
\text { de Bonany }\end{array}$ \\
\hline $\begin{array}{l}\text { maonès / } \\
\text { maonenc (antic) }\end{array}$ & Maó \\
\hline marinenc & el que habita en la \\
\hline
\end{tabular}

\begin{tabular}{|c|c|}
\hline & marina (CC Llucmajor) \\
\hline marrotjar & Marroig (CC Falset) \\
\hline marsalenc & Marçà (CC Falset) \\
\hline mateuer & Sant Mateu d'Aubarca \\
\hline mercadalenc, -ca & Mercadal, es \\
\hline $\begin{array}{l}\text { migjornenc } \\
\text { (antic), } \\
\text { migjorner, ra }\end{array}$ & Migjorn Gran, es \\
\hline miquelers & $\begin{array}{l}\text { Sant Miquel de Balansat } \\
\text { / Eivissa }\end{array}$ \\
\hline molvedrí & Molvedre \\
\hline morellà & Morella \\
\hline muleros & $\begin{array}{l}\text { Mulers (de la Mola, } \\
\text { Formentera) (CC Eivissa) }\end{array}$ \\
\hline murtulons & de Jesús / Eivissa \\
\hline navatencs & Navata \\
\hline nuvellencs & Nuvells (CC Eivissa) \\
\hline ordinesa & Ordino \\
\hline organyanès & Organyà \\
\hline paiportí & Paiporta (CC València) \\
\hline palauencs & $\begin{array}{l}\text { Palau de Noguera (CC } \\
\text { Tremp) }\end{array}$ \\
\hline pallaresos & Pallars (CC Tremp) \\
\hline $\begin{array}{l}\text { patroner } \\
\text { (patronero, } \\
\text { patronera) }\end{array}$ & Patró \\
\hline pegotí, -na & Pego \\
\hline pobletà & Pobla de Lillet, la \\
\hline pobletans & $\begin{array}{l}\text { Pobla de Segur, la (CC } \\
\text { Tremp) }\end{array}$ \\
\hline pontarrí & Pont de Suert, el \\
\hline pontsicà & Ponts \\
\hline porrerà & Porrera (CC Falset) \\
\hline portanyincs & (CC Eivissa) \\
\hline pormanyí & $\begin{array}{l}\text { Sant Antoni de } \\
\text { Portmany (CC Eivissa) }\end{array}$ \\
\hline pradellà & Pradell (CC Falset) \\
\hline rafelers & $\begin{array}{l}\text { Sant Rafel de Forca (CC } \\
\text { Eivissa) }\end{array}$ \\
\hline ravalers & $\begin{array}{l}\text { ravalers (Sant Antoni) } \\
\text { (CC Eivissa) }\end{array}$ \\
\hline ribetà, $-b a$ & $\begin{array}{l}\text { Ribes de Freser ( } Q \\
\text { Campdevànol) }\end{array}$ \\
\hline ripollès, -sa & $\begin{array}{l}\text { Ripoll (CC } \\
\text { Campdevànol) } \\
\end{array}$ \\
\hline rupitencs & Rupit \\
\hline saguntí & Sagunt (CC València) \\
\hline salasencs & Salàs (CC Tremp) \\
\hline
\end{tabular}




\begin{tabular}{|l|l|}
\hline saliners & $\begin{array}{l}\text { Sant Jordi i Sant } \\
\text { Franciscu (CC Eivissa) }\end{array}$ \\
\hline $\begin{array}{l}\text { Sant-Euginians / } \\
\text { taujans }\end{array}$ & Santa Eugènia (Mall.) \\
\hline santaeulariencs & $\begin{array}{l}\text { Santa Eulària des Riu } \\
\text { (CC Eivissa) }\end{array}$ \\
\hline $\begin{array}{l}\text { santantoniencs / } \\
\text { portmanyí }\end{array}$ & $\begin{array}{l}\text { Sant Antoni de } \\
\text { Portmany (CC Eivissa) }\end{array}$ \\
\hline santclimenter & Sant Climent \\
\hline santmartinenc & Sant Martí de Maldà \\
\hline solsoninsos & Solsona \\
\hline $\begin{array}{l}\text { suecà / sóc de } \\
\text { Sueca }\end{array}$ & Sueca \\
\hline tamarità, -ana & Tamarit \\
\hline $\begin{array}{l}\text { tarberners } \\
\text { (tarbeneros) }\end{array}$ & Tàrbena \\
\hline teula(d)ins & Teulada \\
\hline tivissà & Tivissa \\
\hline torrentí & Torrent (CC València) \\
\hline
\end{tabular}

\begin{tabular}{|l|l|}
\hline torretà & Torreta, la (CC Falset) \\
\hline tortosí & Tortosa \\
\hline trempolí & Tremp \\
\hline tureyonenchs & Torelló \\
\hline vilacarlí, na & $\begin{array}{l}\text { Vila-Carlos (es Castell) } \\
\text { (CC Menorca) }\end{array}$ \\
\hline vilafranquer & Vilafranca de Bonany \\
\hline vilafranquí & Vilafranca del Penedès \\
\hline vilencs & Vila (CC Eivissa) \\
\hline vilero & Esporles \\
\hline vileros & Vila Joiosa, la \\
\hline vinarossenc & Vinaròs \\
\hline & $\begin{array}{l}\text { Nadiu o habitant de la } \\
\text { venda Sa Vorera (St. } \\
\text { Antoni de P[ortmany]) }\end{array}$ \\
\hline vorerers & Alcalà de Xivert \\
\hline xivertenc & Xixona (CC Cocentaina) \\
\hline xixonenc &
\end{tabular}


Dialectologia. Special issue, IX (2021), 253-284.

ISSN: 2013-2247

\section{Anexo 2}

Lista de gentilicios que aparecen en el $A L P I$

\begin{tabular}{|c|c|c|}
\hline ademuceros & Ademuz & València \\
\hline ainencos & Aín & Castelló \\
\hline alcorins & Alcora & Castelló \\
\hline ampostins & Amposta & Tarragona \\
\hline anglesencs & Anglès & Gerona \\
\hline arneros & Anna & València \\
\hline asconès & Ascó & Tarragona \\
\hline azueberos & Azuébar & Castelló \\
\hline banyulencs & $\begin{array}{l}\text { Banyuls de la } \\
\text { Marenda } \\
\end{array}$ & $\begin{array}{l}\text { Pyrénées } \\
\text { Orientales }\end{array}$ \\
\hline bassellesos & Bassella & Lleida \\
\hline benioperos & Beniopa & València \\
\hline besalunenc & Besalú & Gerona \\
\hline biarruts & Biar & Alacant \\
\hline billloquins & \begin{tabular}{|l|} 
Bell-Iloc d \\
Urgell \\
\end{tabular} & Lleida \\
\hline blanencs & Blanes & Gerona \\
\hline bordilencs & Bordils & Gerona \\
\hline botencs & Bot & Tarragona \\
\hline cabestanyesos & Cabestany & $\begin{array}{l}\text { Rosselló } \\
\text { (Pyrénées } \\
\text { Orientales) }\end{array}$ \\
\hline cadaquesencs & Cadaqués & Gerona \\
\hline caleros & $\begin{array}{l}\text { La Cala de I } \\
\text { Ametlla } \\
\end{array}$ & Tarragona \\
\hline cALPIns & Calp & Alacant \\
\hline campanès & Campos & Mallorca \\
\hline campdevanolencs & Campdevànol & Gerona \\
\hline campelleros & El Campello & Alacant \\
\hline capdeperins & Capdepera & Mallorca \\
\hline casineros & Casinos & València \\
\hline castellterçolencs & Castellterçol & Barcelona \\
\hline castilleros & $\begin{array}{l}\text { Castillo de } \\
\text { Villamalefa }\end{array}$ & Castelló \\
\hline $\begin{array}{l}\text { catellonins (poco } \\
\text { usado) }\end{array}$ & $\begin{array}{l}\text { Castelló de } \\
\text { Farfanya }\end{array}$ & Lleida \\
\hline caudeteños & $\begin{array}{l}\text { Caudete de } \\
\text { las Fuentes }\end{array}$ & València \\
\hline cauvianès & Calvià & Mallorca \\
\hline cerdans & Bolvir & Gerona \\
\hline
\end{tabular}

\begin{tabular}{|c|c|c|}
\hline cinctorans & Cinctorres & Castelló \\
\hline ciutadellencs & Ciutadella & Menorca \\
\hline clarianesos & Clariana & Lleida \\
\hline clevillenteros & Crevillent & Alacant \\
\hline colomins & \begin{tabular}{|l} 
Santa \\
Coloma de \\
Queralt \\
\end{tabular} & Tarragona \\
\hline cornellanencs & \begin{tabular}{|l} 
Cornellà de \\
Llobregat
\end{tabular} & Barcelona \\
\hline dosagüeros & Dos Aguas & València \\
\hline eivissencs & Eivissa & Eivissa \\
\hline eivissencs & $\begin{array}{l}\text { Sant Joan } \\
\text { Baptista }\end{array}$ & Eivissa \\
\hline encampadans & Encamp & Andorra \\
\hline falsentans & Falset & Tarragona \\
\hline fanzarinos & Fanzara & Castelló \\
\hline felanitxers & Felanitx & Mallorca \\
\hline formiguerencs & Formiguera & $\begin{array}{l}\text { Pyrénées } \\
\text { Orientales }\end{array}$ \\
\hline $\begin{array}{l}\text { ganxos (nombre } \\
\text { jocoso que les dan } \\
\text { los de los pueblos } \\
\text { vecinos) }\end{array}$ & Organyà & Lleida \\
\hline $\begin{array}{l}\text { gentilicio } \\
\text { despectivo } \\
\text { Ilangostes }\end{array}$ & $\begin{array}{l}\text { Vilar de } \\
\text { Canes }\end{array}$ & Castelló \\
\hline golletanos & Godelleta & València \\
\hline granadins & $\begin{array}{l}\text { La Granada } \\
\text { del Penedès }\end{array}$ & Barcelona \\
\hline guardamarencos & Guardamar & Alacant \\
\hline guardians & Guàrdia & Lleida \\
\hline gullenc & Agullana & Gerona \\
\hline Ilanerins & \begin{tabular}{|l} 
Llanera de \\
Ranes
\end{tabular} & València \\
\hline Ilinasencs & \begin{tabular}{|l|} 
Llinars del \\
Vallès \\
\end{tabular} & Barcelona \\
\hline majaero & Dolores & Alacant \\
\hline $\begin{array}{l}\text { mallorquins de } \\
\text { gallinera }\end{array}$ & Benialí & Alacant \\
\hline manacorins & Manacor & Mallorca \\
\hline manuès & Maó & Menorca \\
\hline marineros & Marinas & València \\
\hline
\end{tabular}




\begin{tabular}{|c|c|c|}
\hline $\begin{array}{l}\text { massalavesseros } \\
\text { poco usado }\end{array}$ & Massalavés & València \\
\hline moixentins & Moixent & València \\
\hline molloresos & Molló & Gerona \\
\hline moncofins & Moncofa & Castelló \\
\hline monfortino & Monforte & Alacant \\
\hline monrotxans & $\begin{array}{l}\text { Mont-roig de } \\
\text { Sió }\end{array}$ & Lleida \\
\hline mont-ransencs & Mont-ras & Gerona \\
\hline $\begin{array}{l}\text { muntanyesos de } \\
\text { Senterada }\end{array}$ & Senterada & Lleida \\
\hline orpesins & $\begin{array}{l}\text { Oropesa del } \\
\text { Mar }\end{array}$ & Castelló \\
\hline pallaresos & Rialb & Lleida \\
\hline pedralbinos & Pedralba & València \\
\hline peniscolans & Peníscola & Castelló \\
\hline pinoseros & El Pinós & Alacant \\
\hline $\begin{array}{l}\text { pobletans, } \\
\text { poblencs }\end{array}$ & $\begin{array}{l}\text { La Pobla de } \\
\text { Benifassà }\end{array}$ & Castelló \\
\hline polinyanes & $\begin{array}{l}\text { Polinyà de la } \\
\text { Ribera }\end{array}$ & València \\
\hline pollencins & Pollensa & Mallorca \\
\hline pontarrins & Pont de Suert & Lleida \\
\hline quarteros & $\begin{array}{l}\text { Quart de } \\
\text { Poblet }\end{array}$ & València \\
\hline rabosetes & Aspa & Lleida \\
\hline rodencs & Roda de Berà & Tarragona \\
\hline salsirots & Salses & \begin{tabular}{|l|} 
Rosselló \\
(Pyrénées \\
Orientales) \\
\end{tabular} \\
\hline sammartinencs & $\begin{array}{l}\text { Sant Martí de } \\
\text { Sesgueioles }\end{array}$ & Barcelona \\
\hline $\begin{array}{l}\text { santbartomeus } \\
\text { (solo } \\
\text { humorísticamente) }\end{array}$ & $\begin{array}{l}\text { Sant } \\
\text { Bartomeu del } \\
\text { Grau }\end{array}$ & Barcelona \\
\hline
\end{tabular}

\begin{tabular}{|c|c|c|}
\hline santpedorencs & Santpedor & Barcelona \\
\hline senetans & Senet & Lleida \\
\hline serverins & Son Servera & Mallorca \\
\hline sinevès & Sineu & Mallorca \\
\hline $\begin{array}{l}\text { solleric, plural } \\
\text { suরa' גits }\end{array}$ & Sóller & Mallorca \\
\hline teresanos & \begin{tabular}{|l} 
Teresa de \\
Begís \\
\end{tabular} & Castelló \\
\hline teresinos & $\begin{array}{l}\text { Teresa de } \\
\text { Cofrentes } \\
\end{array}$ & València \\
\hline torisans & Turís & València \\
\hline $\begin{array}{l}\text { trumbaire (es un } \\
\text { apodo) }\end{array}$ & Viladecavalls & Barcelona \\
\hline turinyaires & Taurinyà & \begin{tabular}{|l} 
Pyrénées \\
Orientales \\
\end{tabular} \\
\hline $\begin{array}{l}\text { valencians } \\
\text { pallaresos }\end{array}$ & \begin{tabular}{|l|} 
València d \\
Àneu \\
\end{tabular} & Lleida \\
\hline valldarenesos & La Valldan & Barcelona \\
\hline vila-secans & \begin{tabular}{|l} 
Vila-seca de \\
Solcina, \\
Tarragona \\
\end{tabular} & Tarragona \\
\hline vimbodencs & Vimbodí & Tarragona \\
\hline vistabellans & \begin{tabular}{|l|} 
Vistabella del \\
Maestrat \\
\end{tabular} & Castelló \\
\hline No hay & Llo & $\begin{array}{l}\text { Cerdanya. } \\
\text { Dept. } \\
\text { Pyrénées } \\
\text { Orientales } \\
\end{array}$ \\
\hline $\begin{array}{l}\text { No hay nombre ni } \\
\text { para el pueblo ni } \\
\text { para la comarca }\end{array}$ & Alàs & Lleida \\
\hline$*$ & Arles de Tec & Vallespir \\
\hline$*$ & Benilloba & Alacant \\
\hline$*$ & Rafaelbunyol & València \\
\hline$*$ & Tuéjar & València \\
\hline
\end{tabular}

